\title{
Migraciones internas, inmigración exterior y emigración de españoles hacia el extranjero: un balance por nivel educativo. ¿Es España un país de baja movilidad?
}

\author{
Miguel González-Leonardo \\ Centre d'Estudis Demogràfics \\ Universitat Autònoma de Barcelona. Departament de Geografia \\ mgonzalez@ced.uab.es
}

Recibido: abril de 2019

Aceptado: septiembre de 2019

Publicado: julio de 2020

\section{Resumen}

Los estudios comparativos sostienen que España es un país de baja movilidad interna. Sin embargo, esta afirmación generalista esconde una heterogeneidad geográfica más compleja, pues la intensidad migratoria difiere en función del territorio y del nivel educativo de los individuos. Los balances interprovinciales de población autóctona poco cualificada son, exceptuando las lógicas espaciales de desconcentración, relativamente equilibrados, mientras que la dinámica migratoria de los jóvenes con educación universitaria denota procesos importantes de expulsión y causación acumulativa. En términos cuantitativos, la emigración de españoles hacia el extranjero es poco significativa si se compara con la movilidad interna. La inmigración extranjera, lejos de solventar los desequilibrios territoriales, ha contribuido a alimentar los procesos de acumulación del capital humano cualificado, pues la mayor parte de los alóctonos que se asentaron en las provincias secularmente expulsoras presentan un

* Este trabajo se ha realizado en el marco del Programa de Doctorado en Demografía del Centre d'Estudis Demogràfics y el Departamento de Geografía de la Universitat Autònoma de Barcelona. Ha contado con la financiación de una beca FI de la Generalitat de Catalunya, dentro del proyecto «Integrating Research Infrastructure for European Expertise on Inclusive Growth from Data to Policy» (Union's Horizon 2020. Ref. 730998). También se integra en los proyectos «Comportamientos demográficos y estrategias residenciales: apuntes para el desarrollo de nuevas políticas sociales» (CSO2016-79142-R) y «Movilidad residencial, selección sociodemográfica y substitución de la población: ¿̧hacia la polarización de las ciudades españolas?» (CSO2014-60967-JIN). 
nivel educativo limitado, mientras que los foráneos más cualificados se concentran en las mismas áreas receptoras del talento autóctono.

Palabras clave: migraciones internas; migraciones internacionales; nivel educativo; selectividad educativa; migración diferencial

Resum. Migracions internes, immigració exterior i emigració d'espanyols cap a l'estranger: un balanç per nivell educatiu. És Espanya un país de baixa mobilitat?

Els estudis comparatius sostenen que Espanya és un país de baixa mobilitat interna. Aquesta afirmació generalista amaga una heterogeneïtat geogràfica més complexa, ja que la intensitat migratòria difereix en funció del territori i del nivell educatiu dels individus. Els balanços interprovincials de població autòctona poc qualificada són, exceptuant les lògiques espacials de desconcentració, relativament equilibrats, mentre que la dinàmica migratòria dels joves amb educació universitària denota processos importants d'expulsió i causació acumulativa. En termes quantitatius, l'emigració d'espanyols cap a l'estranger és poc significativa si es compara amb la mobilitat interna. La immigració estrangera, lluny de solucionar aquests desequilibris territorials, ha contribuït a alimentar els processos d'acumulació del capital humà qualificat, ja que la major part de la població nouvinguda que es va assentar a les províncies secularment expulsores presenta un nivell educatiu limitat, mentre que els al.lòctons més qualificats es concentren en les mateixes àrees receptores del talent autòcton.

Paraules clau: migracions internes; migracions internacionals; nivell educatiu; selectivitat migratòria; migració diferencial

Résumé. Analyser les migrations internes, l'immigration étrangère et l'émigration des Espagnols à l'étranger selon le niveau d'éducation. L'Espagne est-elle un pays avec une faible mobilité?

Des études comparatives affirment que l'Espagne est un pays à faible mobilité interne. Cependant, cette affirmation généraliste cache une hétérogénéité géographique plus complexe, notamment car l'intensité migratoire differe selon le territoire et le niveau d'éducation des individus. Par exemple, tandis que les soldes migratoires entre les provinces espagnoles sont relativement équilibrés pour des populations autochtones peu qualifiées, à l'exception des logiques spatiales de la déconcentration, l'analyse de la dynamique migratoire des jeunes diplômés de l'université révèle d'importants processus d'expulsion et de causalité cumulative. En termes quantitatifs, l'émigration des Espagnols à l'étranger est insignifiante par rapport à la mobilité interne. Enfin, en ce qui concerne l'immigration étrangère, elle a contribué à nourrir le processus d'accumulation de capital humain qualifié dans les zones où étaient déjà concentrées les talents autochtones alors que les immigrés les moins qualifiés se sont installés dans les provinces qui séculairement ont un solde migratoire négatif.

Mots-clés: migrations internes; migrations internationales; niveau d'éducation; sélection selon le niveau d'éducation; migration différentielle

Abstract. Internal migration, foreign immigration and out-migration of Spaniards abroad: An analysis by educational attainment. Is Spain a low mobility country?

International comparative studies show that Spain is a country with low internal migration rates. However, this argument hides a remarkable geographic heterogeneity. Migration intensities vary by regions and by individuals' educational attainment. Interprovincial net migration of the less educated native population is well-balanced, except in the case of 
deconcentration dynamics. Nevertheless, the net migration of high-skilled youth shows dramatic losses and cumulative causation processes. International out-migration of Spaniards is low compared to internal flows. International immigration has contributed to concentration processes of human capital: individuals who have come to the traditional sending provinces in Spain have a low educational level, while high skilled-immigrants have arrived to the same areas that attract high skilled Spaniards.

Keywords: internal migration; international migration; educational attainment; educational selectivity; differential migration

\section{Sumario}

1. Introducción 5. Migraciones interprovinciales,

2. La movilidad del capital humano

3. Fuentes y método

4. La dinámica migratoria de las provincias españolas según el nivel educativo. Un análisis de stocks autoctonía-aloctonía y selectividad educativa

6. Conclusiones

Referencias bibliográficas

Anexo

\section{Introducción}

Una vez finalizada la primera transición demográfica en muchos países del mundo, las migraciones han reemplazado al crecimiento natural como principal agente de cambio demográfico (Bell et al., 2015). Durante los primeros años del siglo xxi, España fue uno de los receptores más importantes de inmigración exterior (Reher y Requena, 2011; Recaño, 2002; Arango, 2015; Domingo y Cabré, 2015; López de Lera, 2015; Galeano, 2016). La llegada de extranjeros contribuyó al crecimiento demográfico, al rejuvenecimiento de la estructura etaria y a elevar ligeramente los bajos niveles de natalidad, principalmente en las regiones españolas más pujantes (Domingo, 2016), pero también en los territorios de menor crecimiento demográfico (Delgado-Urrecho y Martínez-Fernández, 2016).

La crisis económica supuso un punto de inflexión, pues trajo consigo la reducción de los flujos de entrada desde el exterior y la salida de algunos foráneos asentados en nuestro país, aunque la mayor parte permanecieron en el territorio (Prieto-Rosas et al., 2018). Al mismo tiempo, la emigración de españoles hacia el extranjero experimentó una tendencia creciente (González-Ferrer, 2013; Herrera-Ceballos, 2014; González-Enríquez y Martínez-Romera, 2017). En cuanto a las migraciones internas de larga distancia —interregionales e interprovinciales_-, estas se incrementan con el cambio de siglo como resultado de dos dinámicas que se producen de manera simultánea: la movilidad de la población extranjera, que presenta intensidades migratorias más elevadas respecto a los locales (Artal et al., 2015; Gil-Alonso et al., 2015; Recaño, 
2016); y la reactivación de la emigración interna entre los jóvenes oriundos de las regiones del interior peninsular y del Cantábrico, principalmente por la fuga del talento local como consecuencia de la creciente sobrecualificación en los territorios de origen (González-Leonardo y López-Gay, 2019a; González-Leonardo at al., 2020).

Dentro del contexto internacional, España es un país de baja movilidad, tanto en lo que se refiere a las migraciones internas (Bentolila, 1997, 2001; Molloy et al., 2011; Bell y Charles-Edwards, 2013; Bell et al., 2015; Artal et al. 2015) como en el caso de la emigración exterior (Docquier y Marfouk, 2006; González-Enríquez y Martínez-Romera, 2017). No obstante, si se desagrega el territorio y se tienen en cuenta algunas características individuales - nivel de estudios, perfil laboral o lugar de nacimiento-, los niveles de movilidad interna no son tan bajos para ciertos colectivos de personas naturales de determinadas comunidades autónomas, como sucede en la emigración de titulados universitarios desde Castilla y León hacia Madrid (González-Leonardo y López-Gay, 2019a, 2019b).

Puesto que el territorio y el nivel de estudios se identifican como variables muy influyentes en la movilidad diferencial, se propone, como primer objetivo de este trabajo, medir la dinámica migratoria interna y externa de las provincias españolas según el logro educativo, comparando ambos tipos de desplazamientos y diferenciando entre individuos autóctonos y alóctonos. Este trabajo pretende dar respuesta a las siguientes preguntas de investigación: ¿qué intensidades emigratorias e inmigratorias se dan en las provincias españolas atendiendo al nivel de instrucción y cuál es el saldo resultante?; ¿qué relevancia tiene la emigración de nativos españoles hacia el exterior en comparación con la movilidad interna?; ¿qué incidencia ha tenido el aporte de la inmigración exterior, en qué medida ha paliado las perdidas demográficas de autóctonos en los territorios secularmente expulsores y en qué grado ha contribuido a alimentar los procesos de causación acumulativa en las áreas receptoras si se tiene en cuenta el logro educativo de los balances migratorios?

El segundo objetivo se centra en medir la probabilidad de cambiar de provincia para la población autóctona y alóctona según el nivel de estudios. La literatura sostiene que los nacidos en el extranjero tienen una mayor movilidad en este tipo de desplazamientos (Reher y Silvestre, 2011; Artal et al., 2015; Gil-Alonso et al., 2015; Recaño, 2016), pero no está del todo claro si esta tendencia se reproduce para las personas de todos los estratos formativos. ¿Tienen los foráneos una intensidad migratoria más alta independientemente del perfil educativo?; ¿hay selectividad migratoria positiva entre la población nacida en España y en el extranjero? Para el análisis, se emplearán los microdatos de dos fuentes del Instituto Nacional de Estadística (INE): el Censo de 2011 y el Padrón de Españoles Residentes en el Extranjero (PERE) de este mismo año. Se calcularán índices de emigración, captación y captación neta, y se emplearán modelos de regresión logística con y sin variables de control. 


\section{La movilidad del capital humano}

\subsection{La dinámica migratoria reciente en España desde una perspectiva internacional}

A partir de la década de 1990, se produce una aceleración de los procesos de globalización y, con ella, un aumento de las migraciones internacionales desde los estados en desarrollo hacia los países desarrollados (Castles et al., 2014; Docquier y Marfouk, 2006). Aparecen nuevos espacios de inmigración, como la Europa mediterránea (Muñoz-Pérez e Izquierdo-Escribano, 1989; Cohen, 1994; Recaño, 2002). Durante los primeros años del siglo Xxi, España se convirtió en uno de los principales receptores de migración internacional, y en 2007 figuraba como el segundo país del mundo con los flujos de entrada más elevados, solo por detrás de los Estados Unidos (OCDE, 2007; Galeano, 2016; Domingo, 2018). La consolidación de España como país de inmigración extranjera supuso un factor decisivo en el sistema migratorio (Reher y Requena, 2011; Arango, 2015; Domingo y Cabré, 2015; López de Lera, 2015), principalmente por la introducción de población foránea directamente desde el extranjero, pero también como resultado de la movilidad interna de estos individuos, que presentan una mayor predisposición a efectuar migraciones interiores respecto a los autóctonos, aunque decreciente con el paso del tiempo (García-Coll, 2005; Recaño y Miguel, 2012; Artal et al., 2015; Gil-Alonso et al., 2015; Recaño, 2016).

A raíz de la crisis económica, aumenta la salida de jóvenes cualificados del sur de Europa hacia otros estados, principalmente en dirección a los países de la Europa noroccidental (González-Ferrer, 2013; Herrera-Ceballos, 2014; Navarrete, 2014; González-Enríquez y Martínez-Romera, 2017). Algunos autores llegaron a afirmar que se trataba de una «nueva oleada de emigración internacional» (Domínguez-Mujica y Pérez-García, 2017; Triyafyllidou y Gropas, 2014). Sin embargo, la creciente movilidad laboral y estudiantil dentro de la Unión Europea no es solo el resultado de la crisis, pues la implementación del programa Erasmus, la internacionalización de las empresas y la facilidad de desplazamiento dentro del espacio Schengen también han tenido un papel importante en este proceso (Tremblay, 2002; Alaminos y Santacreu, 2010).

A escala global y también dentro del contexto español, las migraciones internacionales ocupan una posición preferente en el debate académico, aunque la mayor parte de los cambios de residencia se producen dentro de los límites nacionales (Skeldon, 2008). En el conjunto del planeta, la población que vive en una región distinta a la de nacimiento en el interior del propio país es 3,5 veces superior respecto al monto de individuos que residen en un estado del que no son naturales (Bell y Charles-Edwards, 2013: 12-13). No obstante, las migraciones internas presentan intensidades dispares en los diferentes países del mundo. Los análisis comparativos muestran que los niveles de movilidad entre las unidades administrativas que conforman los estados son más altos en América del Norte, Australia y Europa noroccidental, mientras que en la Europa del Este, el sur de Europa y Asia, salvo excepciones - Japón o Corea del 
Sur-, son más reducidos (Molloy et al., 2011; Bell y Charles-Edwards, 2013; Bell et al., 2015; Bernard et al., 2018). En Sudamérica y el continente africano hay mayor heterogeneidad, con países que presentan niveles elevados - Chile, Zambia, Camerún - y otros con intensidades bajas - Venezuela, Mali, Egipto- (Bell et al., 2015; Bernard et al., 2018). Las migraciones internas están significativamente influenciadas por los desplazamientos internacionales: las ganancias netas con el exterior aumentan la movilidad interna, mientras que las pérdidas generan la dinámica inversa (Bell et al., 2015).

La baja movilidad interregional en los estados del sur de Europa y, por consiguiente, en España tiene su génesis en varios factores. Algunos, en cierto modo, compartidos con otros estados del Viejo Continente y otros no tanto. Se trata de países relativamente heterogéneos desde el punto de vista cultural y, a veces, también lingüísticamente (Cheshire y Magrini, 2006; Gerolimeto y Magrini, 2018). Los vínculos familiares y las redes sociales locales juegan un papel determinante y se traducen en un fuerte arraigo territorial (Spilimbergo y Ubeda, 2004; González-Enríquez y Martínez-Romera, 2017). El mercado inmobiliario, carente de un stock público en alquiler y con elevadas tasas de propiedad con hipoteca, dificulta el acceso a la vivienda y la rotación residencial (Oswald, 1999; Azevedo et al., 2016; Gerolimeto y Magrini, 2018). La intensidad de las migraciones también se asocia con el calendario en los distintos eventos del ciclo de vida (Bernard et al., 2014). La emancipación tardía del hogar paterno, propia del arco mediterráneo, está ligada a una disminución generalizada de la movilidad (López-Gay, 2004; Molloy et al., 2011; Bell et al., 2015), de igual modo que sucede con el retraso de la maternidad sobre los niveles de fecundidad.

Por otro lado, también se da una escasa movilidad estudiantil de larga distancia (Rodríguez-Rodríguez y Domínguez-Mujica, 2019), lo que, a su vez, disminuye la probabilidad de realizar migraciones encadenadas. Dentro del mundo desarrollado, la movilidad geográfica de los estudiantes es muy característica del contexto estadounidense en la etapa de formación universitaria y menos común en los estados europeos y Oceanía, donde la mayor parte de los jóvenes cursan sus estudios superiores en las universidades locales (Bell et al., 2002) o en las más próximas al lugar de residencia de los padres cuando no disponen de centros formativos o de una oferta suficientemente amplia de titulaciones en el lugar de origen (Reques-Velasco, 2007). Como resultado, la inmovilidad y la baja intensidad migratoria están fuertemente arraigadas en las sociedades de la Europa meridional, tanto en lo que se refiere a la emigración desde el lugar de residencia como a los movimientos migratorios posteriores, la movilidad encadenada desde una perspectiva longitudinal (Puga, 2004; Bernard y Vidal, 2019).

Los estudios comparativos entre Europa y los Estados Unidos señalan que los factores no económicos (blandos) —oferta de ocio, cosmopolitismo, clima - tienen un peso destacado en la movilidad interna de los estadounidenses, mientras que en el Viejo Continente no son tan relevantes, y los factores económicos (duros) —salario, empleo- desempeñan un papel 
prioritario (Partridge y Rickman, 2003, 2006; Cheshire y Magrini, 2006). Los marcados desequilibrios territoriales dentro de los países del sur de Europa son determinantes en las migraciones internas de la población, pues las oportunidades económicas se reparten de forma muy desigual, lo que favorece que los factores duros tengan una mayor relevancia en las motivaciones para migrar (Gerolimeto y Magrini, 2018).

Pese a que los factores blandos no son, a priori, demasiado importantes en la decisión de emigrar, sí serían influyentes a la hora de fijar población en destino una vez efectuado el movimiento migratorio, previa consideración de los factores económicos (Rodríguez-Pose y Ketterer, 2012). Si bien existen evidencias empíricas de una relación directa entre oportunidades laborales y diferencias salariales con las migraciones internas en Europa, no sucede lo mismo respecto a las tasas de desempleo (Bentivogli y Pagano, 1999). Los territorios con altas proporciones de parados, al contrario que en EE. UU., no son los que presentan los niveles más elevados de emigración (Maczulskij et al., 2018), ni en el conjunto de Europa (Bentivogli y Pagano, 1999) ni en el caso concreto de España (Antolín y Bover, 1997; Bover y Velilla, 1999). En este aspecto, la extensión del estado del bienestar y la protección social de las personas en paro, junto al apoyo familiar y otros determinantes ya mencionados, influyen notablemente en la inmovilidad geográfica de los desempleados (Antolín y Bover, 1997; Belot et al., 2007).

\subsection{Selectividad educativa y migraciones}

Ravenstein (1885), Thomas (1938), Roy (1951) y Sjaastad (1962) son los primeros académicos en introducir el concepto de selectividad en el estudio de las migraciones y concluyen que los migrantes no son una muestra representativa del conjunto de la población en origen, sino que se trata de individuos positivamente seleccionados. Cuanto mayor es el capital humano individual, más altos son los réditos derivados de la movilidad, pues la capacidad para obtener mejores salarios y oportunidades laborales se incrementa (Sjaastad, 1962; Harris y Todaro, 1970; Stark y Bloom, 1985; Borjas et al., 1992; Massey y Espinosa, 1997). El flujo de información es más abundante y disminuyen los costes de la migración (Greenwood, 1975; Greenwood y Hunt, 2003). También se asocia con la ampliación de las redes sociales y, por tanto, migratorias (Palloni et al., 2001), y aumenta el individualismo en detrimento de los lazos familiares, las tradiciones y el arraigo local (Amuakwa-Mensah et al., 2016).

Dentro de los factores que afectan a la selectividad migratoria, el logro educativo se identifica como uno de los más relevantes (World Bank, 2009). El grueso de las aportaciones que han estudiado la relación entre movimientos migratorios y nivel de instrucción concluye que las personas con un mayor logro educativo son más propensas a cambiar de residencia (Sjaastad, 1962; Long, 1973; Gould, 1982; Speare y Harris, 1986; Borjas et al., 1992; Hatton y Williamson, 2004; Docquier y Marfouk, 2006; Cattaneo, 2007; Williams, 2009; Wozniak, 2010; Machin et al., 2012; Malamud y Wozniak, 2012; 
Săseanu y Petrescu, 2012; Bernard y Bell, 2018; Bernard et al., 2018), que la selectividad aumenta con la distancia recorrida (Schwartz, 1973; Long, 1973; Gould, 1982; Hatton y Williamson, 2004; Cattaneo, 2007; Malamud y Wozniak, 2012) y que un nivel de instrucción superior se traduce en un mayor número de movimientos (Gould, 1982).

Bernard y Bell (2018) realizan un estudio comparativo sobre la selectividad educativa de los migrantes internos en los distintos países del mundo y obtienen evidencias empíricas de una correlación positiva y exponencial. Los resultados corresponden a la curva en forma de J descrita por Gould (1982), que es más pronunciada en los países desarrollados: unos pocos años de educación aumentan ligeramente la tendencia a emigrar y un logro educativo elevado hace que la predisposición a la movilidad crezca de manera exponencial. Por regiones, obtienen niveles más elevados de selectividad en Europa y América del Norte y menores en América Latina. No obstante, se aprecian notables diferencias entre países dentro de la misma región, pues la dinámica migratoria y la selectividad están fuertemente afectadas por el contexto económico y social de cada estado (Oucho, 1998; Ginsburg et al., 2016; Bernard y Bell, 2018).

Unos pocos estudios manifiestan una relación negativa entre nivel de instrucción y movilidad (Massey y Espinosa, 1997; Quinn y Rubb, 2005; Clarke y Eyal, 2013; Reed, 2013; Rendall y Parker, 2014). Lee (1966) señala que existen flujos migratorios seleccionados positiva y negativamente y hace hincapié en los factores de atracción-repulsión como marco explicativo: si la motivación principal deriva de los factores de atracción en destino, la selección será positiva; si, por el contrario, son los factores de empuje en origen los más relevantes, será negativa. Chiswick (2000) afirma que únicamente en el caso de los migrantes económicos existe selección positiva. Rendall y Parker (2014) sostienen que solamente algunos colectivos de inmigrantes están positivamente seleccionados y apuntan al caso de estudio de los mexicanos en los Estados Unidos como ejemplo de selectividad negativa. Por otra parte, las políticas migratorias del lugar de destino afectan al grado de selectividad de los inmigrantes (Chiswick, 2000; Cattaneo, 2007). Otros autores señalan que la selectividad es positiva en la primera etapa migratoria, en el caso de los pioneros, pero, a medida que las redes y la reagrupación familiar cobran mayor importancia, se reduce, incluso puede cambiar a signo negativo (Massey, 1987; 1999; Feliciano, 2005).

Ginsburg et al. (2016) analizan la selectividad educativa en varios países del continente africano y obtienen resultados dispares. Concluyen que la hipótesis de la selectividad migratoria no es universal y que la movilidad de la población más educada dependerá de la localización de la oferta de trabajo cualificado y esta, a su vez, de las características del tejido productivo en cada territorio, que atraerá o expulsará población de acuerdo con los requerimientos locales de mano de obra (Vreyer y Roubaud, 2013; Ginsburg et al., 2016). Las personas más instruidas no migran si no tienen incentivos para ello (Feliciano, 2005; Ginsburg et al., 2016): mejores salarios en destino, empleo... Por otra parte, hay que considerar que puede darse la relación inversa: la movilidad podría ser 
un objetivo para aumentar el logro educativo. Aunque, generalmente, la literatura apunta a que la migración se efectúa una vez el individuo ha adquirido un nivel considerable de capital humano en origen (Bernard et al., 2018), y estar estudiando suele disminuir la probabilidad de moverse (Williams, 2009).

\section{Fuentes y método}

Se utilizan los microdatos de dos fuentes del INE: el Censo de 2011 y el PERE de este mismo año. A partir de estas bases de datos, se hace un análisis de stocks migratorios internos y externos por provincias para la población de 25 a 34 años, ya que se quiere estudiar la movilidad de la población adulta joven. En el caso del Censo, se distingue entre personas nacidas en España y en otros países. Para definir la movilidad interna de los primeros, se utiliza la provincia de nacimiento y la provincia de residencia actual, y para los segundos, la provincia de residencia anterior y la actual. Si ambas coinciden, se trata de una persona sedentaria; en caso contrario, el individuo en cuestión sería un migrante interprovincial. La elección de la provincia de nacimiento para los locales viene motivada por el interés de medir el balance total del fenómeno migratorio desde el lugar de origen y no tanto teniendo en cuenta las migraciones encadenadas. Sin embargo, también se calcularon los resultados usando la provincia de residencia anterior y estos no variaban demasiado, lo que corrobora la afirmación del apartado anterior sobre la baja movilidad desde el punto de vista longitudinal. En ambos colectivos, autóctonos y alóctonos, se establecen dos niveles educativos: titulados universitarios y no universitarios. Para los nativos españoles en el exterior, los registrados en el PERE, también se acota el rango etario indicado. Esta fuente no dispone de la desagregación de estudios universitarios en la variable referente al logro formativo y únicamente recoge hasta bachillerato o superior.

En cuanto a los problemas derivados en las fuentes utilizadas, hay que considerar que, al tratarse de un stock, se pierden los movimientos intermedios y, por lo tanto, las migraciones siempre estarán subestimadas. Puesto que se realiza un análisis provincial, no es posible diferenciar la movilidad de arrastre que llegó con sus progenitores a edades tempranas y tampoco sabemos dónde han obtenido el logro educativo actual los migrantes. El Censo dispone de la variable año de llegada a la comunidad autónoma y al municipio, pero no a la provincia. Sin embargo, la intensidad migratoria de etapas anteriores ha sido bastante baja y de carácter mayoritariamente individual, por lo que la movilidad de arrastre es poco significativa (Recaño, 2015).

Una parte considerable de los jóvenes oriundos de provincias con una oferta de titulaciones limitada se desplaza para cursar estudios superiores, y esto tiene una incidencia significativa en el hecho de residir en un territorio distinto al de nacimiento con posterioridad. En las provincias con una amplia oferta formativa, este tipo de movilidad no tiene demasiada incidencia, pues la mayor parte de los jóvenes optan por las universidades locales (Rodríguez-Rodríguez y Domínguez-Mujica, 2019) y emigran una vez han obtenido el título 
universitario en origen (Bell et al., 2002). En cuanto al PERE, teóricamente es obligatorio inscribirse para los españoles que residen fuera de España más de tres meses, pero no existen mecanismos de sanción contra el incumplimiento de esta norma (González-Enríquez y Martínez-Romera, 2017). Varias encuestas han revelado que el subregistro se sitúa entre el 35\% (González-Enríquez, 2013) y el 55\% (Romero-Valiente e Hidalgo-Capitán, 2014), aunque disminuye con el tiempo de estancia, cuando el proyecto migratorio se consolida. Tras 5 años de residencia, el subregistro cae al 17\% (Gropas y Triandafyllidou, 2014).

Para medir la intensidad migratoria en las distintas provincias, se elaboran tres indicadores: índice emigratorio $\left(\mathrm{I}_{\mathrm{em}}\right)$, índice de captación $\left(\mathrm{I}_{\text {cap }}\right)$ e índice de captación neta $\left(\mathrm{I}_{\text {capN }}\right)^{1}$. El primero representa la proporción de emigrantes. El I $\mathrm{I}_{\text {cap }}$ es una ratio entre las personas llegadas a la provincia y los individuos nativos de esta que residen en ella, eliminando del denominador a los emigrados autóctonos. Se interpreta como la capacidad de atracción respecto a la población endógena que vive en el territorio: si el índice es 0,1 , significa que por cada diez nativos sedentarios ha llegado un efectivo. El I $\mathrm{c}_{\text {capN }}$ tiene el mismo denominador que el $\mathrm{I}_{\text {cap }}$, pero en el numerador se calcula el balance entre las personas llegadas de otros lugares y la población local emigrada: si es 0,1 , la provincia habría ganado 1 individuo por cada 10 autóctonos sedentarios; si es $-0,2$, habrá perdido 2 personas por cada 10 nativos residentes.

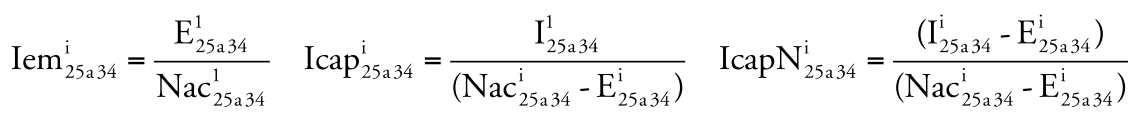

$\mathrm{E}_{25}^{\mathrm{i}}$ a 34 : emigrantes entre 25 y 34 años de la región i. $\mathrm{Nac}^{\mathrm{i}}{ }_{25}$ a 34 : nacidos en la región i del grupo etario $25-34 . \mathrm{I}_{25}^{\mathrm{i}}$ a 34 : inmigrantes de 25 a 34 años que llegan a la región i.

Tras un análisis descriptivo a través de los indicadores citados, se realizan varios modelos de regresión logística aplicados a los microdatos del Censo de 2011. Inicialmente, se mide la probabilidad de cambiar de provincia (variable explicada) para la población autóctona y la alóctona (variable explicativa) del rango etario estudiado, estableciendo el primer colectivo como categoría de referencia. Se quiere observar si existen diferencias según el nivel educativo, por lo que se aplica una regresión para tres poblaciones en riesgo de manera aislada: primero para todos los niveles formativos de manera conjunta y después para universitarios y no universitarios por separado.

Seguidamente, se realiza un modelo para medir la selectividad educativa interprovincial (variable explicativa) de los jóvenes nativos y foráneos. Se establecen cinco categorías: primaria o inferior, EGB-ESO-CFGM (ciclo for-

1. Los indicadores no son comparables entre sí, pues los denominadores utilizados en el índice de captación y el índice de captación neta son diferentes respecto al índice de emigración. Los dos primeros son una ratio y el tercero una proporción. 
mativo de grado medio + FP1), bachillerato-CFGS (ciclo formativo de grado superior + FP2), diplomatura o grado y, por último, licenciatura y máster o superior. Tanto para la probabilidad migratoria como para la selectividad, se realizan dos modelos, el primero sin variables de control y el segundo introduciendo las que describe la literatura como más relevantes — sexo, estado civil, empleo, si estudia o no (Sjaastad, 1962; Amuakwa-Mensah et al., 2016)—y algunas que se consideran influyentes dentro del contexto español: lugar de trabajo, sectores económicos, región de nacimiento cuando la población en riesgo está compuesta solo por foráneos y tipo de provincia emisora (ver tablas 4 y 5 del anexo). La categorización de esta última variable responde a la intensidad emigratoria de la misma — baja emisión cuando la expulsión relativa es moderada, media cuando los valores están cerca del promedio nacional y alta cuando es elevada - y al porcentaje de universitarios — bajo, próximo a la media y alto-.

\section{La dinámica migratoria de las provincias españolas según el nivel educativo. Un análisis de stocks}

Si se tiene en cuenta únicamente la dinámica migratoria de la población autóctona, hay un balance negativo en 32 de las 50 provincias (tabla 1) y se observan intensidades de emigración e inmigración muy diferentes. Guadalajara y Toledo, en términos relativos y gracias a la dinámica centrífuga del Área Metropolitana de Madrid, fueron los territorios con un saldo migratorio más favorable. Gerona, Tarragona, Castellón, Alicante, Baleares, el archipiélago canario, Madrid, Almería y Málaga también tuvieron ganancias netas significativas. En números absolutos, Barcelona fue la unidad administrativa con el balance más deficitario, aunque el índice de captación neta no denota grandes pérdidas relativas. El saldo negativo de población endógena alcanza una entidad muy importante en 6 provincias de Castilla y León y en otras del norte de España - Orense, Vizcaya, Guipúzcoa-y del interior peninsular —Cuenca, Teruel—.

Al comparar los balances de autóctonos por migración interna y la emigración de estos hacia el exterior, los datos del PERE muestran pérdidas poblacionales bastante bajas. En el año 2011, había 42.000 nativos del rango etario estudiado inscritos en el PERE, frente a 914.000 que residían en una provincia diferente a la de nacimiento dentro del territorio español, un $4,4 \%$ y un $95,6 \%$, respectivamente. A pesar de que no había ninguna unidad administrativa con un índice de emigración exterior destacado, las provincias gallegas de La Coruña, Orense y Pontevedra fueron las más emisoras. De cualquier modo, no hay que obviar que existe un subregistro importante en el PERE. Los principales destinos fueron los estados de la Europa noroccidental, entre los que destacan Reino Unido, Francia, Suiza y Alemania, que sumaban 30.000 personas, el $71,6 \%$. Globalmente, los Estados Unidos se situaban en tercer lugar, por detrás del país galo.

Al incluir el stock de población nacida en el extranjero y residente en España en el balance total, tan solo 11 provincias tuvieron un saldo negati- 
Tabla 1. Stocks, balance migratorio, índices de emigración, captación y captación neta de las provincias españolas para la población de 25 a 34 años, por lugar de nacimiento y tipo de movilidad, 2011

\begin{tabular}{|c|c|c|c|c|c|c|c|c|c|c|c|c|}
\hline \multirow[b]{2}{*}{ Provincia } & \multicolumn{6}{|c|}{ Autóctonos: migraciones interprovinciales } & \multicolumn{2}{|c|}{$\begin{array}{l}\text { Autóctonos: } \\
\text { em. exterior }\end{array}$} & \multicolumn{2}{|c|}{$\begin{array}{l}\text { Inm. alóctonos } \\
\text { en España }\end{array}$} & \multicolumn{2}{|c|}{ Balance total } \\
\hline & Emi. & $\mathrm{I}_{\mathrm{e}}$ & Inm. & $\mathrm{I}_{\text {cap }}$ & Balance & $\mathrm{I}_{\text {capN }}$ & Emi. & $\mathrm{I}_{\mathrm{e}}$ & Inm. & $\mathrm{I}_{\text {cap }}$ & Balance & $\mathrm{I}_{\text {capN }}$ \\
\hline Zamora & 8.552 & 0,36 & 3.750 & 0,24 & -4.802 & $-0,31$ & 116 & 0,00 & 1.962 & 0,13 & -2.956 & $-0,19$ \\
\hline Salamanca & 15.803 & 0,33 & 7.948 & 0,25 & -7.855 & $-0,25$ & 434 & 0,01 & 4.723 & 0,15 & -3.567 & $-0,11$ \\
\hline Jaén & 23.289 & 0,23 & 9.948 & 0,13 & -13.342 & $-0,17$ & 341 & 0,00 & 5.648 & 0,07 & -8.035 & $-0,10$ \\
\hline Palencia & 7.170 & 0,31 & 3.761 & 0,23 & -3.409 & $-0,21$ & 128 & 0,01 & 1.896 & 0,12 & -1.642 & $-0,10$ \\
\hline Córdoba & 23.697 & 0,20 & 12.103 & 0,13 & -11.594 & $-0,12$ & 426 & 0,00 & 6.412 & 0,07 & -5.608 & $-0,06$ \\
\hline Ourense & 11.347 & 0,28 & 4.695 & 0,16 & -6.653 & $-0,23$ & 918 & 0,02 & 6.164 & 0,21 & -1.406 & $-0,05$ \\
\hline Vizcaya & 36.434 & 0,23 & 11.414 & 0,09 & -25.020 & $-0,20$ & 1.205 & 0,01 & 20.558 & 0,17 & -5.667 & $-0,05$ \\
\hline Cáceres & 15.197 & 0,28 & 10.417 & 0,27 & -4.780 & $-0,12$ & 287 & 0,01 & 3.470 & 0,09 & -1.598 & $-0,04$ \\
\hline Guipúzcoa & 20.205 & 0,22 & 8.131 & 0,11 & -12.074 & $-0,17$ & 1.330 & 0,01 & 10.634 & 0,15 & -2.770 & $-0,04$ \\
\hline León & 17.264 & 0,27 & 9.197 & 0,20 & -8.067 & $-0,17$ & 510 & 0,01 & 7.032 & 0,15 & -1.545 & $-0,03$ \\
\hline Cádiz & 30.607 & 0,16 & 20.326 & 0,13 & -10.280 & $-0,07$ & 951 & 0,01 & 11.007 & 0,07 & -224 & 0,00 \\
\hline Badajoz & 18.801 & 0,19 & 12.581 & 0,16 & -6.221 & $-0,08$ & 340 & 0,00 & 6.832 & 0,09 & 272 & 0,00 \\
\hline Asturias & 22.152 & 0,16 & 11.926 & 0,10 & -10.225 & $-0,09$ & 1.126 & 0,01 & 14.745 & 0,13 & 3.394 & 0,03 \\
\hline Soria & 3.901 & 0,37 & 2.064 & 0,31 & -1.837 & $-0,27$ & 70 & 0,01 & 2.250 & 0,33 & 344 & 0,05 \\
\hline Lugo & 8.607 & 0,20 & 6.643 & 0,20 & -1.965 & $-0,06$ & 273 & 0,01 & 4.109 & 0,12 & 1.872 & 0,06 \\
\hline Ávila & 7.062 & 0,37 & 5.005 & 0,41 & -2.057 & $-0,17$ & 71 & 0,00 & 2.823 & 0,23 & 695 & 0,06 \\
\hline Pontevedra & 17.973 & 0,14 & 14.670 & 0,13 & -3.303 & $-0,03$ & 1.801 & 0,01 & 11.865 & 0,11 & 6.761 & 0,06 \\
\hline A Coruña & 22.359 & 0,15 & 18.502 & 0,15 & -3.857 & $-0,03$ & 2.618 & 0,02 & 14.548 & 0,12 & 8.072 & 0,06 \\
\hline Ciudad Rea & 14.949 & 0,21 & 10.885 & 0,19 & -4.064 & $-0,07$ & 200 & 0,00 & 9.2 & 6 & 50 & 0,09 \\
\hline Valladolid & 14.862 & 0,22 & 12.968 & 0,24 & -1.894 & $-0,04$ & 548 & 0,01 & 7.634 & 14 & 5.192 & 0,10 \\
\hline Sevilla & 29.553 & 0,11 & 34.867 & 0,14 & 5.314 & 0,02 & 1.186 & 0,00 & 20.647 & 0,09 & 24.775 & 0,10 \\
\hline Albacete & 11.243 & 0,21 & 7.905 & 0,19 & -3.338 & $-0,08$ & 20 & 0,00 & 8.028 & 9 & 4.488 & 0,11 \\
\hline Granada & 26.419 & 0,21 & 21.021 & 0,21 & -5.398 & $-0,05$ & 763 & 0,01 & 17.936 & 0,18 & 11.774 & 0,12 \\
\hline Cantabria & 11.417 & 0,15 & 10.636 & 0,16 & -782 & $-0,01$ & 486 & 0,01 & 9.195 & 0,14 & 7.927 & 0,12 \\
\hline Burgos & 12.467 & 0,28 & 8.646 & 0,27 & -3.821 & $-0,12$ & 314 & 0,01 & 8.272 & 6 & 4.137 & 0,13 \\
\hline Cuenca & 8.958 & 0,34 & 5.419 & 0,31 & -3.539 & $-0,20$ & 79 & 0,00 & 6.575 & 0,38 & 2.957 & 0,17 \\
\hline Huelva & 8.216 & 0,12 & 10.714 & 0,18 & 2.498 & 0,04 & 218 & 0,00 & 11.063 & 0,18 & 13.343 & 0,22 \\
\hline Valencia & 35.056 & 0,11 & 32.377 & 0,11 & -2.678 & $-0,01$ & I.841 & 0,01 & 70.831 & 0,25 & & 0,23 \\
\hline Teruel & 5.877 & 0,38 & 4.303 & 0,44 & -1.574 & $-0,16$ & 71 & 0,00 & 4.042 & 0,42 & 2.397 & 0,25 \\
\hline Segovia & 5.379 & 0,30 & 4.104 & 0,33 & -1.275 & $-0,10$ & 93 & 0,01 & 4.609 & 0,37 & 3.242 & 0,26 \\
\hline Álava & 9.229 & 0,24 & 9.607 & 0,33 & 378 & 0,01 & 245 & 0,01 & 8.027 & 0,28 & 8.159 & 0,28 \\
\hline Barcelona & 102.083 & 0,15 & 63.548 & 0,11 & -38.535 & $-0,07$ & 6.172 & 0,01 & 208.351 & 0,37 & 163.644 & 0,29 \\
\hline Las Palmas & 10.071 & 0,08 & 18.741 & 0,15 & 8.671 & 0,07 & 736 & 0,01 & 29.645 & 0,24 & 37.580 & 0,30 \\
\hline Huesca & 7.597 & 0,31 & & 0,3 & -1.467 & $-0,09$ & 128 & 0,01 & 6.6 & 0,40 & 5.099 & 0,31 \\
\hline Sta. Cruz de Tf. & 6.808 & 0,06 & 14.623 & 0,13 & 7.815 & 0,07 & 600 & 0,01 & 30.613 & 0,28 & 37.829 & 0,35 \\
\hline Murcia & 16.398 & 0,09 & 21.636 & 0,13 & 5.237 & 0,03 & 648 & 0,00 & 52.468 & 0,33 & 57.057 & 0,35 \\
\hline Zaragoza & 18.186 & 0,17 & 17.254 & 0,20 & -932 & $-0,01$ & 868 & 0,01 & 33.130 & 0,38 & 31.330 & 0,36 \\
\hline Navarra & 10.290 & 0,15 & 12.823 & 0,22 & 2.534 & 0,04 & 472 & 0,01 & 19.479 & 0,33 & 21.541 & 0,37 \\
\hline Málaga & 15.727 & 0,09 & 38.390 & 0,24 & 22.663 & 0,14 & 1.041 & 0,01 & 42.553 & 0,26 & 64.175 & 0,40 \\
\hline La Rioja & 6.697 & 0,20 & 7.493 & 0,28 & 796 & 0,03 & 213 & 0,01 & 11.938 & 0,45 & 12.521 & 0,47 \\
\hline Alicante & 19.021 & 0,10 & 39.835 & 0,24 & 20.814 & 0,12 & 973 & 0,01 & 60.120 & 0,36 & 79.961 & 0,48 \\
\hline Madrid & 117.820 & 0,16 & 149.260 & 0,25 & 31.441 & 0,05 & 7.647 & 0,01 & 267.785 & 0,44 & 291.579 & 0,48 \\
\hline Lleida & 9.950 & 0,22 & 9.417 & 0,26 & -533 & $-0,01$ & 485 & 0,01 & 19.281 & 0,53 & 18.263 & 0,51 \\
\hline Castellón & 6.521 & 0,11 & 16.818 & 0,32 & 10.296 & 0,20 & 274 & 0,00 & 22.422 & 0,43 & 32.444 & 0,62 \\
\hline Almería & 8.729 & 0,12 & 17.500 & 0,27 & 8.771 & 0,13 & 309 & 0,00 & 33.171 & 0,51 & 41.633 & 0,64 \\
\hline Tarragona & 13.644 & 0,17 & 26.231 & 0,40 & 12.587 & 0,19 & 547 & 0,01 & 30.998 & 0,47 & 43.038 & 0,65 \\
\hline Baleares & 9.656 & 0,09 & 34.131 & 0,35 & 24.475 & 0,25 & 662 & 0,01 & 52.932 & 0,55 & 76.745 & 0,79 \\
\hline Toledo & 15.922 & 0,23 & 36.872 & 0,70 & 20.950 & 0,40 & 200 & 0,00 & 21.632 & 0,41 & 42.382 & 0,80 \\
\hline Girona & 10.806 & 0,16 & 21.166 & 0,38 & 10.360 & 0,18 & 494 & 0,01 & 36.282 & 0,65 & 46.148 & 0,82 \\
\hline Guadalajara & 4.218 & 0,24 & 17.418 & 1,27 & 13.200 & 0,97 & 76 & 0,00 & 11.037 & 0,81 & 24.162 & 1,77 \\
\hline
\end{tabular}

Fuente: Censo de Población y Padrón de Españoles Residentes en el Extranjero, 2011 (Instituto Nacional de Estadística). 
vo y las pérdidas se redujeron considerablemente en todas ellas. Sin embargo, en algunos casos, como en Zamora, Salamanca, Jaén y Palencia, el déficit migratorio continuó siendo palpable. De igual modo que sucedía respecto a la población española, la ganancia en los territorios septentrionales de Castilla-La Mancha fue muy abundante. También en Madrid, la Comunidad Valenciana, Cataluña, los archipiélagos y algunas provincias del sur y del interior donde existen nichos laborales concretos, cuya demanda es atendida por población extranjera. En líneas generales, la inmigración exterior ha supuesto una revitalización demográfica para el conjunto del país, aunque su llegada y su redistribución por el territorio han tenido lugar de forma desigual. En las provincias con una dinámica poblacional recesiva, ayudó a paliar la salida de efectivos nacionales, pero, al mismo tiempo, contribuyó a alimentar los procesos de acumulación en las principales áreas receptoras de nativos españoles.

$\mathrm{Al}$ analizar las intensidades de emigración y captación según el nivel educativo (personas con y sin universitarios), se observa que la dinámica migratoria de las provincias españolas es bastante más compleja. Los datos del PERE, por la escasa entidad del stock y al no disponer del nivel de instrucción universitario en la variable referente al logro educativo, se excluyen del análisis. Es necesario remarcar que la mayor parte de los nativos residentes en el exterior tienen el máximo nivel formativo que recoge el PERE — bachillerato o superior-, aunque, en cualquier caso, este flujo de salida ha quedado más que compensado con la inmigración extranjera, tanto para la población en general como para los individuos con un nivel educativo elevado.

Los mapas de la figura 1 (tabla 1 del anexo) representan la movilidad interprovincial de la población autóctona entre 25 y 34 años. En primer lugar, es destacable que la intensidad emigratoria es mucho más intensa entre los titulados superiores de los territorios secularmente expulsores (figuras $1.1 \mathrm{y}$ 1.2). En las provincias de Castilla y León, a excepción de Valladolid, que no está muy alejada de estos valores, más de un 35\% de los locales con titulación universitaria habían emigrado, de igual modo que en Orense, Cáceres, Cuenca, Huesca, Teruel y Jaén. En Ávila, Palencia, Salamanca, Segovia, Soria y Zamora, la proporción superaba el $45 \%$. Otras provincias del interior y de la cornisa cantábrica también registraron intensidades emigratorias altas para la población más instruida.

En cuanto al índice de captación, figuras 1.3 y 1.4, los territorios circundantes a Madrid y Barcelona tenían las intensidades más altas para el nivel educativo sin estudios universitarios, lo que denota un marcado carácter de selectividad migratoria negativa desde las provincias donde se sitúan las dos ciudades globales españolas hacia sus áreas limítrofes. En el caso de los titulados superiores, estas provincias periféricas también succionan población a costa de los espacios centrales, aunque en menor medida. Madrid atrae un contingente muy importante de universitarios. También Valladolid, Salamanca, Segovia - cuyas capitales tienen un peso relativamente destacado en la órbita regional, y por el efecto denominador derivado de una elevada emi- 
gración-, Málaga y Almería. Las Islas Baleares captan población de ambos estratos educativos.

En las figuras 1.5 y 1.6 se observa el resultado de la dinámica comentada entre emigración e inmigración. El índice de captación neta para los no universitarios es muy elevado en las provincias septentrionales de Castilla-La Mancha y, en menor medida, en Gerona, Tarragona y Castellón. En el resto del territorio, las pérdidas o las ganancias no fueron demasiado significativas, y las salidas quedaron prácticamente compensadas con las entradas. El balance migratorio de la población con estudios universitarios, sin embargo, es mucho más desigual y los desequilibrios territoriales son más palpables a través de la movilidad del capital humano altamente formado.

Todas las provincias de Castilla y León presentaban un balance migratorio negativo, especialmente acusado en Zamora, Salamanca, Ávila, Soria, Palencia y León. Las pérdidas que evidencia el $\mathrm{I}_{\mathrm{capN}}$ en estos territorios son el resultado de una dinámica emigratoria intensa y de una escasa afluencia desde otros lugares. Pese a que Valladolid, Salamanca, y Segovia recibieron cierta afluencia de universitarios de otras partes de la región, las salidas fueron mucho más cuantiosas. Otras provincias de la mitad sur, el norte y el interior nororiental también se vieron afectadas por la pérdida de titulados universitarios. Madrid y Baleares, junto con Guadalajara, por desconcentración, registraron los índices netos de captación más altos y se consolidan como los principales focos de atracción. Barcelona, de manera relativa, no atrae demasiada población con estudios universitarios procedente del resto de España, aunque fue la provincia que menos autóctonos con estas mismas características expulsó hacia otras partes del país.

La figura 2 (tabla 2 del anexo) representa la dinámica migratoria de los jóvenes alóctonos residentes en el territorio español en el Censo de 2011: la captación directa hacia el exterior, la captación por movilidad interna y la emigración interprovincial. En primer lugar, es destacable que la atracción hacia la población extranjera por migración interna es, por el menor tamaño de esta, escasa en comparación con los valores registrados para los autóctonos, y también la captación exterior de individuos con estudios universitarios, por lo que se ha ajustado la leyenda de las figuras 2.1, 2.2, 2.3 y 2,4 respecto a los rangos dados en la figura $1^{2}$. La captación en las provincias españolas hacia personas nacidas en otros países se ha dado, principalmente, por inmigración directa desde el exterior y la mayor parte de la ganancia poblacional ha sido a costa de la llegada de foráneos sin estudios universitarios, canalizada hacia el litoral mediterráneo, Madrid y sus provincias limítrofes, los archipiélagos y la mitad nororiental de la Península (figura 2.1).

La afluencia relativa de alóctonos con titulación universitaria desde el extranjero ha sido más cuantiosa en Barcelona, Santa Cruz de Tenerife,

2. Hay que tener presente que el índice de captación es una ratio de atracción poblacional respecto a los autóctonos residentes en la provincia de nacimiento y, por lo tanto, el denominador está compuesto también por estos en el indicador calculado para los alóctonos. No en el índice de emigración, que tiene en el denominador a los foráneos. 
Figura 1. Índices de emigración, captación y captación neta interprovincial para la población autóctona de 25 a 34 años (+ valores absolutos), por nivel educativo, 2011

Fig. 1.1. Índice de emigración (no universitarios)

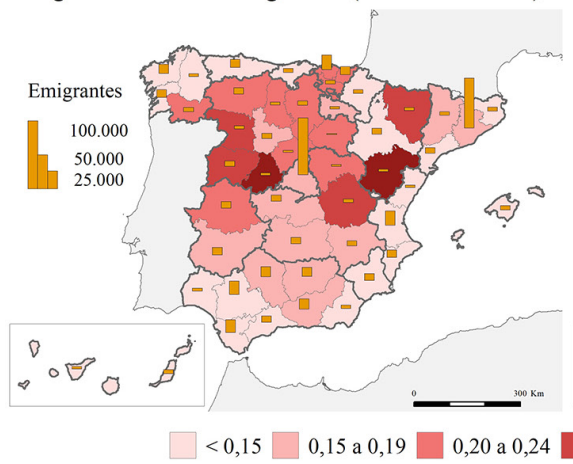

Fig. 1.3. Índice de captación (no universitarios)

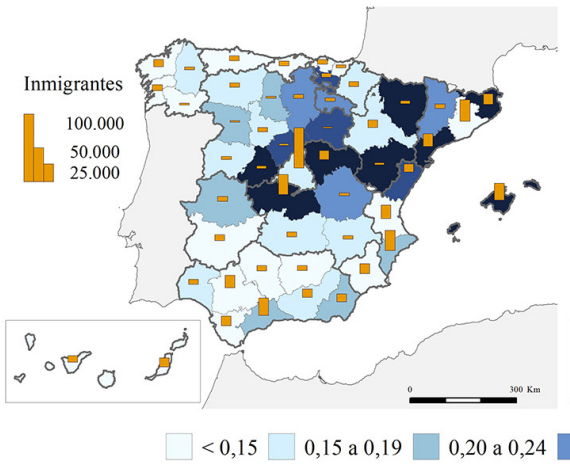

Fig. 1.5. Índice de captación neta (no universitarios)

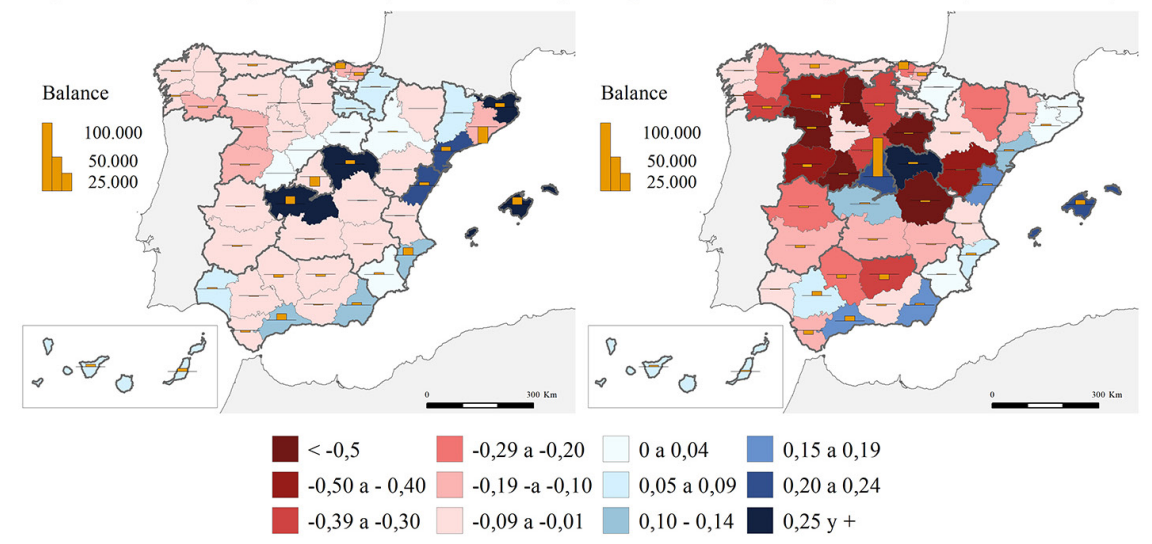

Fig. 1.2. Índice de emigración (universitarios)

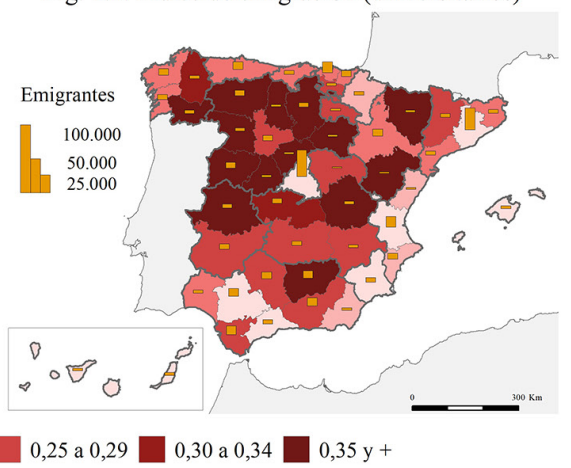

Fig. 1.4. Índice de captación (universitarios)

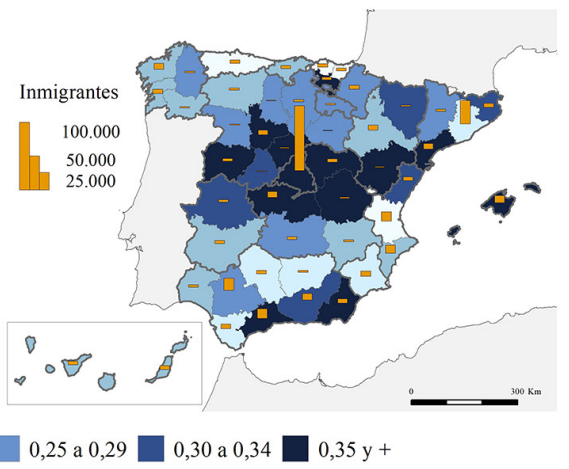

Fig. 1.6. Índice de captación neta (universitarios)

Fuente: Censo de 2011 (Instituto Nacional de Estadística). 
Madrid, Baleares, Las Palmas, Málaga, Gerona y Tarragona (figura 2.2). En el caso de los archipiélagos y el sur de España, el efecto denominador, por el menor nivel de instrucción de la población endógena, hace que los índices sean más elevados. En Madrid sucede lo contrario, pues el logro educativo de los jóvenes locales es de los más altos de todo conjunto nacional. En números absolutos, Barcelona y Madrid captaron el mayor contingente de foráneos universitarios, en torno a 60.000 en ambos casos, aunque la atracción relativa de Barcelona es más elevada.

En cuanto a la captación interna, la mayor ganancia de extranjeros sin estudios universitarios se dio en las provincias limítrofes con Madrid y Barcelona y responde a una lógica de expulsión desde los lugares centrales, donde el coste de vida es elevado, hacia territorios periféricos más económicos (figura 2.3). Las dos provincias globales actúan, en un primer momento, como puerta de entrada para los inmigrantes llegados directamente desde el exterior y, posteriormente, algunos de ellos se mueven hacia unidades administrativas colindantes. La captación de extranjeros con titulación universitaria por migración interna es muy escasa y apenas tiene representatividad en términos cuantitativos (figura 2.4).

En el caso de la emigración interprovincial, si se comparan los $I_{e m}$ de los foráneos sin estudios universitarios (figura 2.5) con los de los autóctonos de este mismo estrato educativo (figura 1.1), se observa que existe una mayor movilidad entre los primeros. En referencia a los titulados superiores, los índices de emigración de los alóctonos (figura 2.6), generalmente, se asemejan bastante a los de población nacida en España (figura 1.2). De igual modo que sucede entre los locales, los extranjeros con un nivel de instrucción superior emigran más que sus homólogos de menor logro educativo en la mayor parte de los territorios emisores. Se puede concluir que los extranjeros más cualificados llegaron directamente a las áreas españolas más pujantes y no se han redistribuido por el territorio español. Mientras tanto, del escaso contingente de foráneos instruidos que arribó a las provincias secularmente expulsoras, una buena parte se marchó siguiendo las pautas migratorias internas de la población local. También algunos de los que llegaron a España a edades tempranas y se formaron en estos territorios.

En la figura 3 (tabla 3 del anexo), se representa el índice de captación neta total para la población autóctona y alóctona de manera conjunta. Es decir, el saldo por migración interna de los jóvenes nacidos en España más el stock total de foráneos, que resulta de la llegada directa de estos desde el exterior y su posterior redistribución. En la figura 3.1, se grafica el balance total de personas sin estudios universitarios, que se asemeja al mapa de la figura $2.1 \mathrm{y}$ muestra ganancias netas en casi todo el Estado, salvo en Zamora, Córdoba y Jaén, donde el balance negativo fue escaso. Madrid y las provincias que la rodean, la mitad nororiental de la Península, el litoral mediterráneo y los archipiélagos fueron los sectores más beneficiados. Los flujos migratorios exteriores que llegaron a España durante la etapa expansiva de la inmigración extranjera estaban compuestos mayoritariamente por personas sin estudios universitarios, 
Figura 2. Índices de captación exterior, captación interna y emigración interna para la población alóctona entre 25 y 34 años (+ valores absolutos), por nivel educativo, 2011

Fig. 2.1. Índice de captación exterior (no univ.)

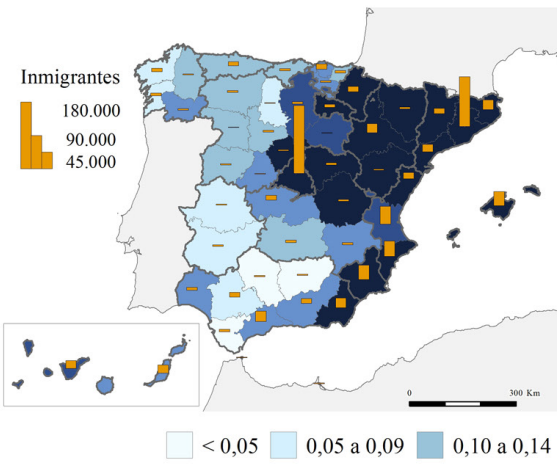

Fig. 2.3. Índice de captación interna (no univ.)

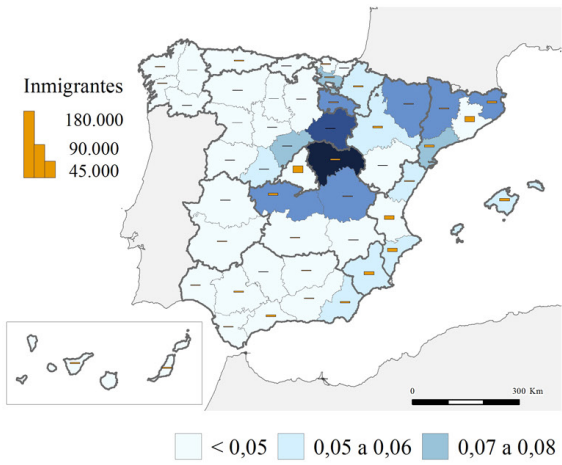

Fig. 2.2. Índice de captación exterior (universitarios)

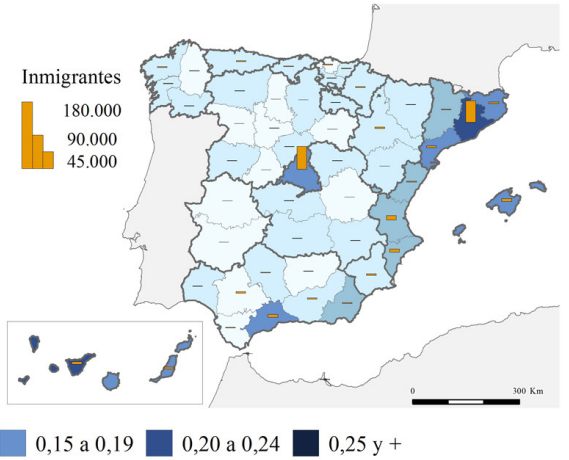

Fig. 2.4. Índice de captación interna (universitarios)

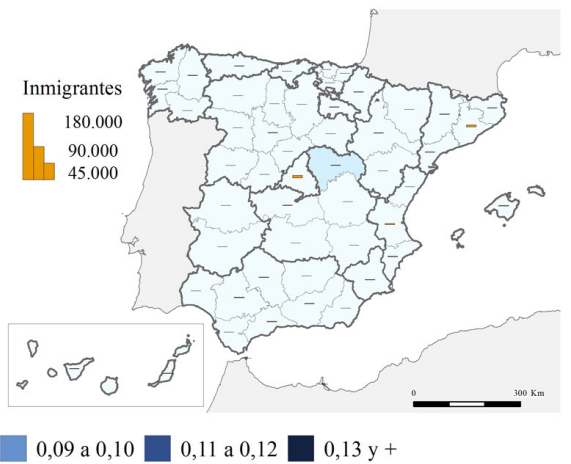

Fig. 2.5. Índice de emigración interna (no univ.)

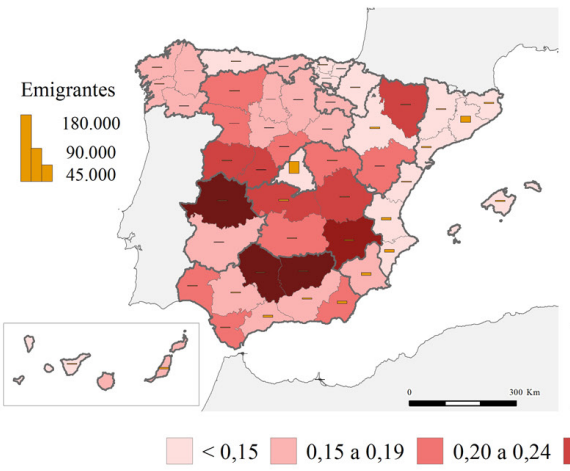

Fig. 2.6. Índice de emigración interna (universitarios)

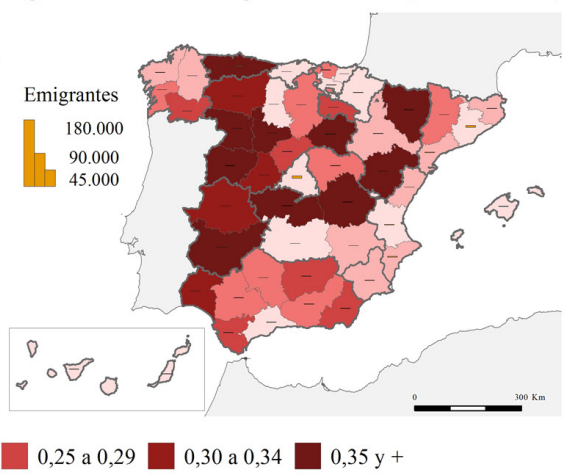

Fuente: Censo de 2011 (Instituto Nacional de Estadística). 
Figura 3. Índice de captación neta total (autóctonos + alóctonos) para la población de 25 a 34 años (+ balance absoluto de nativos y foráneos), por nivel educativo, 2011

Figura 3.1. Indice de captación neta (no universitarios)

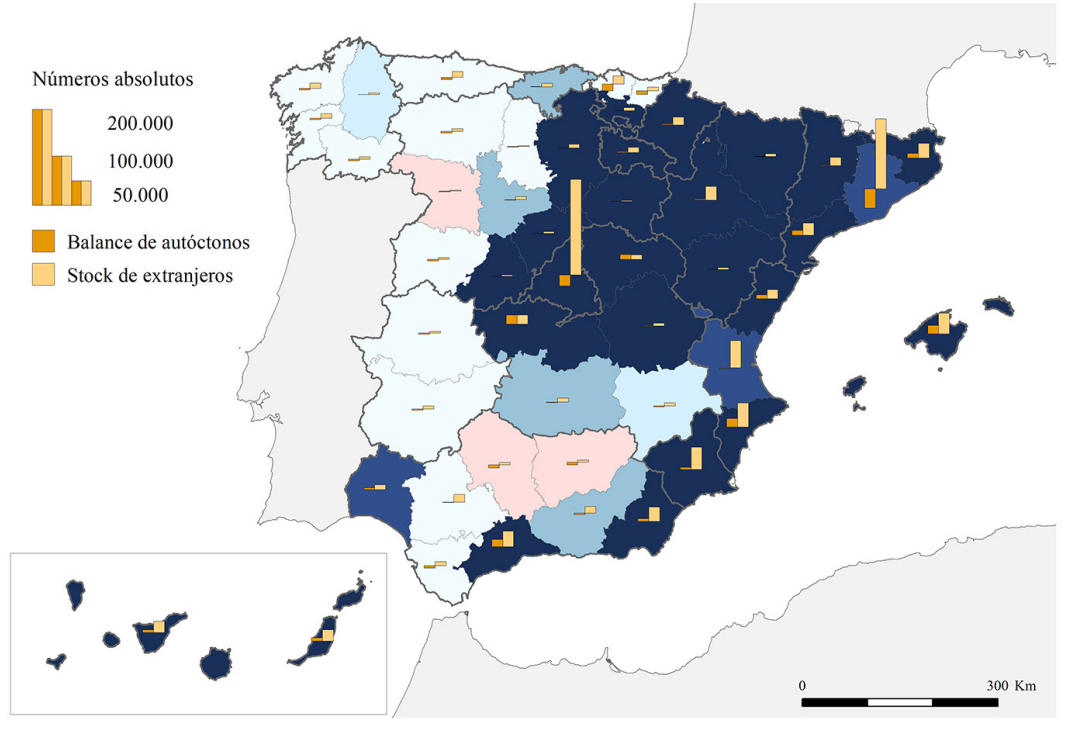

Figura 3.2. Índice de captación neta (universitarios)

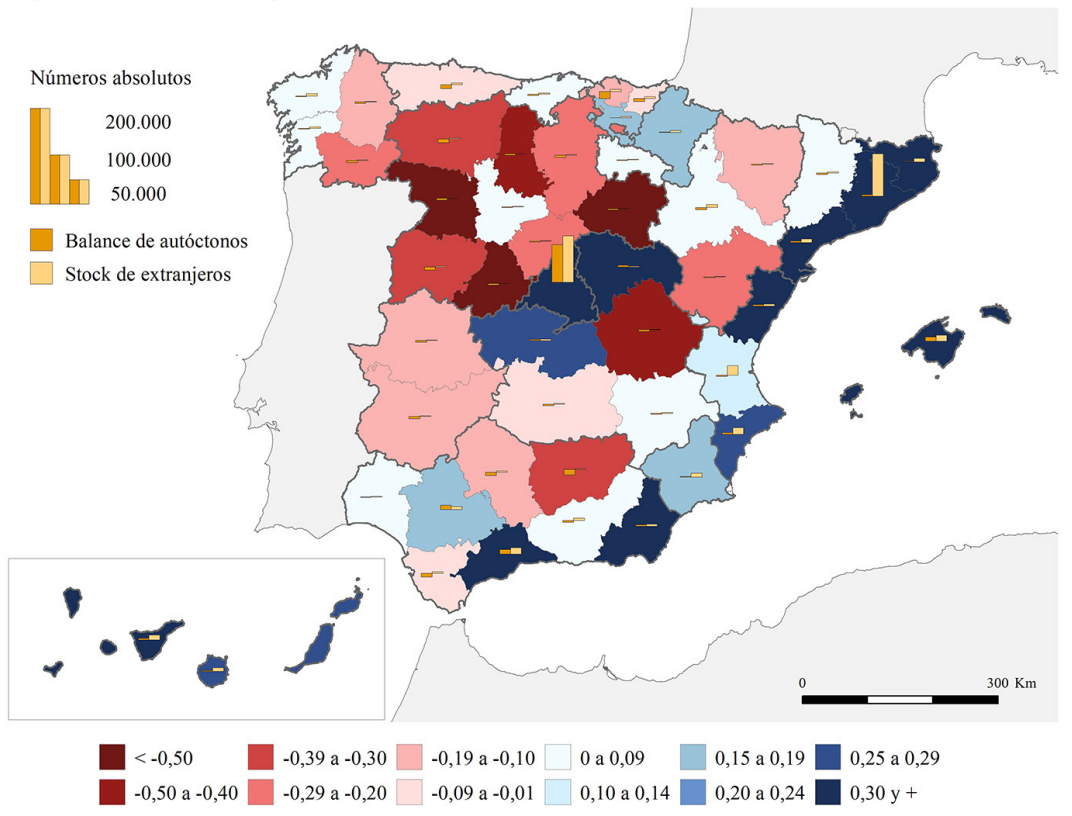

Fuente: Censo de 2011 (Instituto Nacional de Estadística). 
y han sido el factor más influyente en la dinámica migratoria de este estrato educativo, pues los saldos de españoles no universitarios no denotan grandes pérdidas o ganancias netas significativas, a excepción de los procesos de desconcentración referidos.

La figura 3.2 refleja el balance total de jóvenes con estudios universitarios. El índice de captación neta es positivo en Madrid, Barcelona y sus provincias circundantes: Guadalajara, Toledo, Gerona y Tarragona. También en la Comunidad Valenciana, Baleares, Canarias, Málaga y Almería. El noroeste peninsular, Extremadura, Aragón y la mitad sur de Castilla-La Mancha registraron un saldo negativo de titulados universitarios bastante representativo. Nuevamente, el índice de captación neta de Castilla y León esboza un déficit migratorio muy importantes de jóvenes con estudios universitarios en casi todo el territorio. Dicho indicador alcanza un valor negativo de $-0,76$ en Soria, - -0,6 en Zamora y -0,51 en Ávila, unas pérdidas relativas considerables e impropias de un país de baja movilidad. En este caso, las migraciones internas de los titulados universitarios autóctonos constituyen el factor dominante en la distribución territorial del capital humano altamente cualificado. También, aunque en menor medida, la llegada directa de expats desde el exterior hacia las provincias más dinámicas.

Por consiguiente, aunque el aporte de población alóctona ha paliado la pérdida de nativos por emigración interna en la mayor parte de las provincias secularmente emisoras, no ha compensado, ni mucho menos, la salida del capital humano altamente cualificado hacia las áreas españolas económicamente más pujantes. Los flujos exteriores que llegaron a los territorios de menor crecimiento demográfico estaban compuestos por individuos con un nivel educativo inferior al de la población local residente y mucho más bajo que el de los migrantes internos españoles. Por otra parte, el asentamiento de los foráneos se ha materializado de forma muy desigual en las distintas provincias, lo que ha contribuido a perpetuar y acrecentar los desequilibrios demográficos, sobre todo si se tiene en cuenta el nivel educativo. El grueso de los extranjeros, principalmente de los más instruidos, se concentró en las áreas receptoras más importantes, entre las que destacan las provincias de Madrid y Barcelona.

\section{Migraciones interprovinciales, autoctonía-aloctonía y selectividad educativa}

A continuación, se mide la probabilidad de cambiar de provincia de residencia para los jóvenes autóctonos y alóctonos según el nivel de estudios (figura 4 y tabla 4 del anexo). El modelo aplicado al conjunto de la población corrobora los resultados que esboza la literatura sobre migraciones internas, que otorga a los foráneos una mayor movilidad. Las personas nacidas en el extranjero y con estudios inferiores al universitario también tienen una probabilidad más alta que los locales de residir en una provincia diferente, en torno a un 35\%. Sin embargo, en el caso de los jóvenes con estudios universitarios sucede lo 
Figura 4. Odds ratio con un IC del 95\% para la emigración interprovincial de la población entre 25 y 34 años (total, no universitarios y universitarios). Factor explicativo: lugar de nacimiento

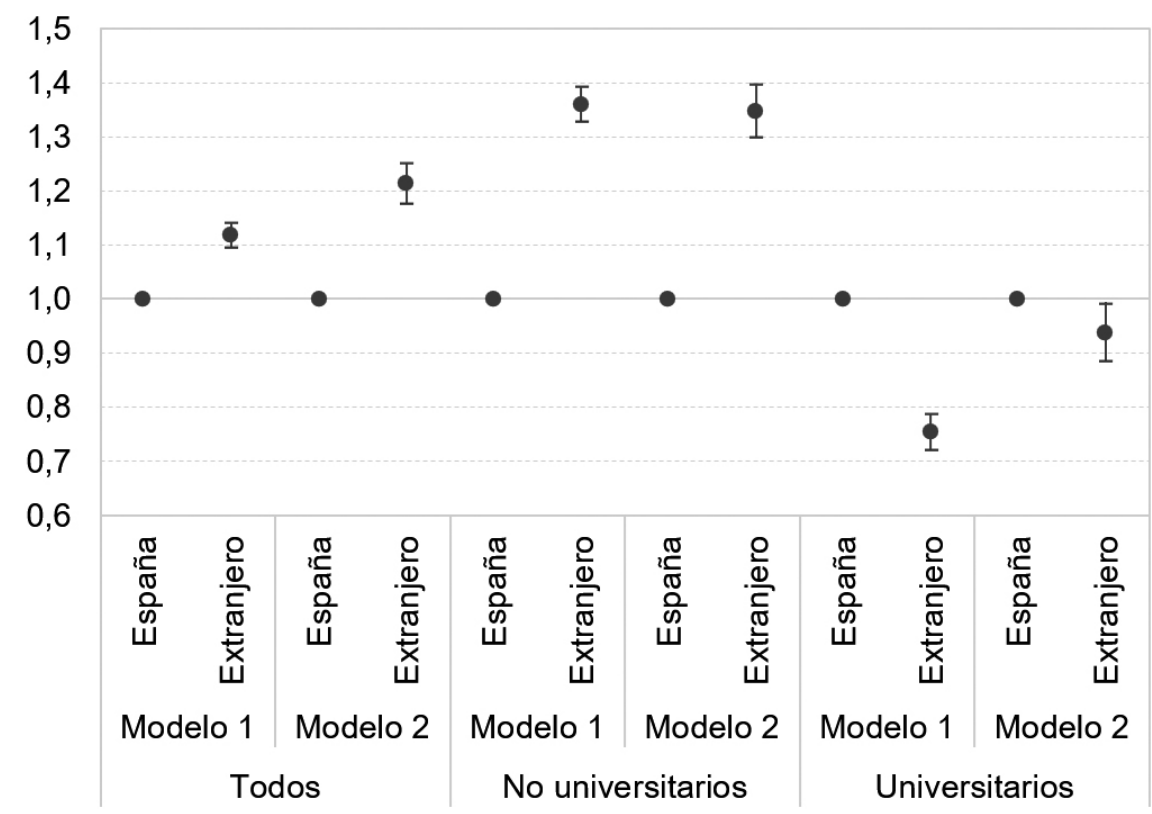

Variables de control para el modelo 2: sexo, estado civil, estudia o no, situación profesional, sectores económicos, lugar de trabajo y tipología de la provincia de residencia anterior.

Fuente: Censo de 2011 (Instituto Nacional de Estadística).

contrario: los nativos españoles con titulación superior se mueven más que los alóctonos, cuya odds ratio (OR) es un 25\% superior en el modelo 1 y un 5\% en el modelo 2.

La variable de control referente a la tipología de la provincia de residencia anterior acerca a la unidad la OR de los foráneos universitarios y evidencia que la movilidad interprovincial de los titulados superiores está fuertemente influenciada por las características migratorias y el logro educativo de la provincia emisora en cuestión, una tendencia que refuerza los resultados descriptivos de los índices de emigración analizados en el apartado anterior. La situación profesional y el sector económico de actividad también tienen cierta incidencia sobre todas las OR en general, pero no es demasiado destacada.

En la figura 5 (tabla 5 del anexo), se mide la selectividad migratoria interprovincial y se observa que los patrones de movilidades de los jóvenes autóctonos presentan la selectividad positiva y exponencial que describe la literatura, con la característica forma en J (Gould, 1982; Bernard y Bell, 2018). Entre los foráneos, no se aprecia esta misma tendencia, sino que, antes de introducir las variables de control, hay una relación más bien negativa. Esta deja de ser 
Figura 5. Odds ratio con un IC del 95\% para la emigración interprovincial de la población entre 25 y 34 años (autóctonos y alóctonos). Factor explicativo: educación

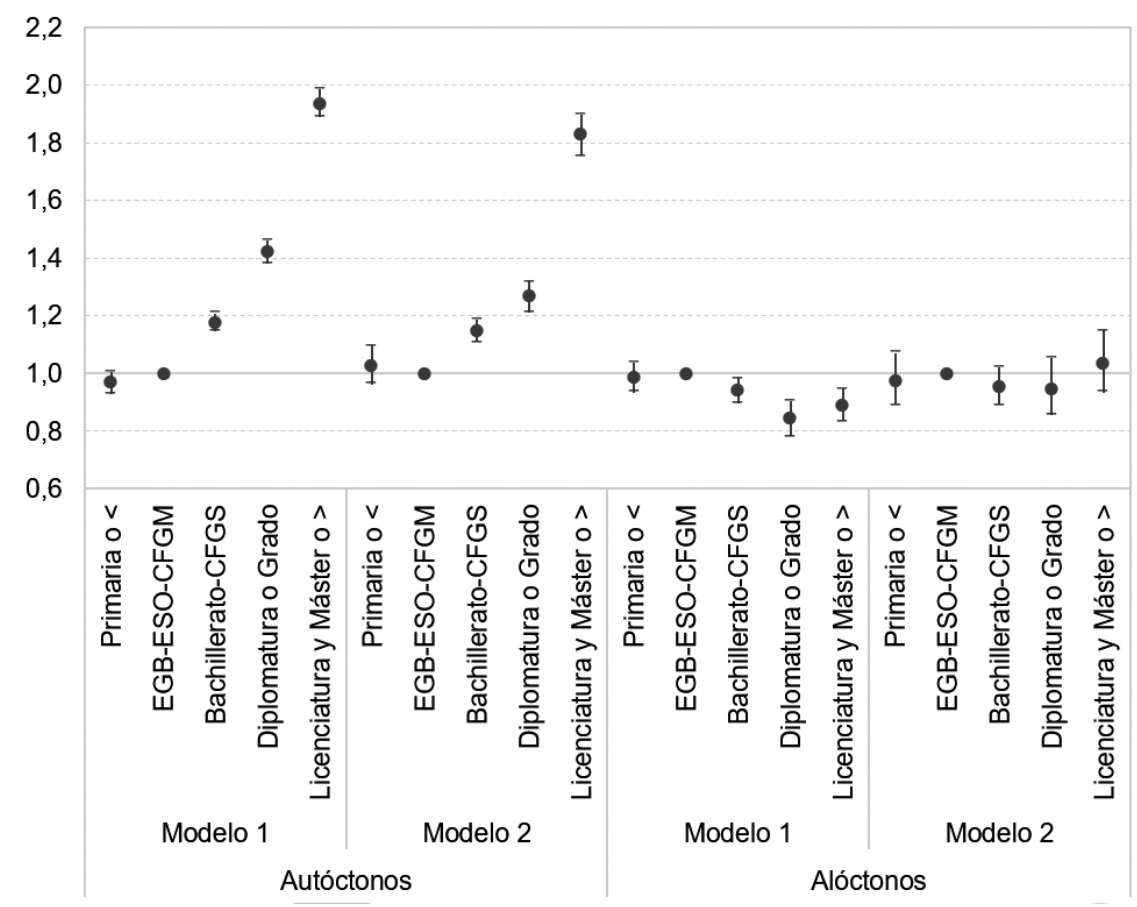

Variables de control para el modelo 2: sexo, estado civil, estudia o no, situación profesional, sectores económicos, lugar de trabajo, tipología de la provincia de residencia anterior y región de nacimiento para los alóctonos.

Fuente: Censo de 2011 (Instituto Nacional de Estadística).

significativa en el modelo 2 a consecuencia de los mismos factores que eran relevantes en el caso anterior. En este aspecto, los argumentos explicativos que esbozan los índices migratorios darían respuesta a la selectividad negativa de los alóctonos: la mayor parte de los inmigrantes exteriores más instruidos llegaron directamente desde el extranjero a las provincias económicamente más pujantes; mientras que una buena parte de los menos cualificados que arribaron a estos territorios se marcharon hacia las provincias periféricas limítrofes con un coste de vida más bajo. En los territorios secularmente expulsores, sí habría selectividad positiva en la emigración interna de los foráneos.

\section{Conclusiones}

A pesar de la baja movilidad interna que argumenta la literatura y que manifiestan las cifras totales, si se tiene en cuenta el territorio y el nivel educativo de los sujetos, se observa una dinámica migratoria heterogénea oculta bajo el 
agregado de distintas lógicas espaciales. Respecto a la población nacida en Espana, los individuos sin estudios universitarios presentan intensidades migratorias interprovinciales bajas y balances relativamente equilibrados, a excepción de la ganancia poblacional del norte de Castilla-La Mancha por desconcentración del Área Metropolitana de Madrid. Los autóctonos españoles con estudios universitarios, sin embargo, presentan saldos migratorios mucho más desequilibrados y se observan dinámicas de expulsión muy marcadas en las provincias secularmente emisoras, con intensidades emigratorias altas e impropias de un país catalogado como «de baja movilidad». Cabrer et al. (2009), GonzálezLeonardo y López-Gay (2019b) y González-Leonardo et al. (2019, 2020) también concluyen en sus investigaciones que la movilidad del capital humano cualificado es más desigual.

Las provincias de Castilla y León son las más afectadas, con un 35\% de jóvenes autóctonos con titulación universitaria emigrados en otras partes de España, y más de un 45\% en Ávila, Palencia, Salamanca, Segovia, Soria y Zamora. El tejido productivo de estos territorios acusa un importante déficit de actividades tecnológicas y puestos de trabajo cualificados, que, junto a un elevado nivel educativo de los jóvenes, se traduce en un marcado desajuste entre el perfil formativo de la población y la oferta laboral, lo que genera elevados niveles de sobrecualificación y la fuga de graduados universitarios (GonzálezLeonardo y López-Gay, 2019b).

Respecto a la emigración de nativos españoles hacia el exterior, las cifras del PERE, en comparación con los datos sobre migraciones internas del Censo, muestran que se trata de un tipo de movilidad cuantitativamente poco relevante. El 95,6\% del stock de población autóctona entre 25 y 34 años que residía fuera de su provincia de nacimiento se localizaba en otros territorios dentro del país, y tan solo un 4,4\% en el extranjero. Madrid se consolida como el principal receptor de población española con estudios universitarios. La capital y su área de influencia urbana succionan el talento nacional procedente de regiones periféricas y suministradoras de mano de obra altamente cualificada, una conclusión similar a obtenida por SánchezMoral et al. (2018) usando la Muestra Continua de Vidas Laboral en su análisis. Esta dinámica pone de relieve la existencia de un modelo centroperiferia (Seers et al., 1979; Williams et al., 2004) y fuertes procesos de causación acumulativa (Myrdal, 1957; Massey, 1990). No es baladí que las personas son más propensas a emigrar cuanto mayor es el desajuste entre sus habilidades y los retornos pagados por ellas en las regiones de origen, y los lugares que ofrecen más oportunidades laborales y mejores réditos atraen un contingente más elevado y seccionado de población (Borjas et al., 1992; Fielding, 1992).

En términos generales, la afluencia de inmigración extranjera ayudó a paliar la salida de efectivos nacionales en las provincias con una dinámica demográfica recesiva, pero, al mismo tiempo, contribuyó a alimentar los procesos de concentración en las principales áreas receptoras de nativos españoles. Si se tiene en cuenta el nivel educativo, no ha compensado, ni de lejos, el 
éxodo de titulados universitarios en las provincias emisoras. Solo unos pocos de los alóctonos que llegaron a estos lugares tenían estudios universitarios y muchos de ellos se han marchado reproduciendo las pautas migratorias internas de los locales. Los foráneos más cualificados arribaron directamente desde el exterior a las áreas más pujantes y no se han redistribuido por el territorio. La provincia de Barcelona, a pesar del poco atractivo que despierta para los migrantes internos oriundos de otras partes de España, es el principal receptor de extranjeros cualificados, seguida de Madrid. Los datos analizados llegan hasta 2011, pero algunos estudios que utilizan fuentes no publicadas más recientes —altas padronales de los ayuntamientos según el nivel de instrucción - recogen una afluencia creciente de universitarios hacia las dos ciudades globales españolas (López-Gay, 2016a; 2016b; López-Gay y Andújar-Llosa, 2019).

La dinámica migratoria en España, atendiendo al nivel educativo, se configura por dos tipos dominantes de movilidad que dibujan la distribución territorial del capital humano a través de procesos de expulsión y atracción. La inmigración exterior es el principal factor a la hora de reubicar mano de obra poco cualificadas, exceptuando el proceso de desconcentración hacia Guadalajara y Toledo, en el que también participa un contingente importante de nativos españoles. La localización territorial de la población altamente cualificada, sin embargo, se configura por las migraciones interprovinciales de autóctonos españoles y, en menor medida, por la llegada directa desde el exterior de extranjeros cualificados a Barcelona y Madrid.

La mayor movilidad interna de las personas nacidas en el extranjero que argumenta la literatura no se da en todos los estratos educativos para las migraciones interprovinciales: los alóctonos con un nivel de instrucción inferior al universitario se mueven más que los nativos, pero los titulados autóctonos tienen una mayor probabilidad de migrar en comparación con los foráneos. Por consiguiente, los españoles altamente cualificados se consolidan como el colectivo más móvil. No obstante, al controlar por la tipología de la provincia de origen, la movilidad diferencial en favor de los locales universitarios se acorta, pues dicha dinámica no se produce en todos los territorios por igual, sino que depende de las características de la provincia en cuestión.

En cuanto a la selectividad migratoria, las pautas de movilidad de los autóctonos se suman a los estudios sobre selectividad positiva y exponencial, pero no las de los extranjeros, para los que no se aprecia una correlación claramente definida y, en caso de observarse alguna, esta sería más bien negativa. Dicha tendencia sugiere que la selectividad no siempre ha de ser positiva y que depende del contexto origen-destino (Ginsburg et al., 2016). En este caso, tiene mucho que ver el proceso centrífugo de Madrid, que expulsa población de los estratos educativos más bajos como consecuencia del elevado coste de vida. Esta dinámica constituye un factor de empuje muy importante y corrobora la hipótesis de Lee (1966): la selectividad será positiva si la motivación principal deriva de elementos de atracción en destino, y negativa si los factores de empuje en origen son más influyentes. 


\section{Referencias bibliográficas}

Alaminos, Antonio y Santacreu, Oscar (2010). «La emigración cualificada española en Francia y Alemania». Papers. Revista de Sociología, 95, 201-211. <https://doi.org/10.5565/rev/papers/v95n1.678>

Amuakwa-Mensah, Franklin; Boakye-Yiadom, Louis y BaAh-Boateng, William (2016). "Effect of education on migration decisions in Ghana: a rural-urban perspective». Journal of Economic Studies, 43 (2), 336-356. <https://doi.org/10.1108/jes-09-2013-0138>

Antolín, Pablo y Bover, Olympia (1997). «Regional Migration in Spain: the Effect of Personal Characteristics and of Unemployment, Wage and House Price Differentials using Pooled Cross-sections». Oxford Bulletin of Economics and Statistics, 59, 215-235. <https://doi.org/10.1111/1468-0084.00061>

Arango, Joaquín (2015). «España: una experiencia inmigratoria singular». En: TorRES, Cristóbal (ed.). España 2015. Situación social, 268-275. Madrid: CIS.

Artal, Andrés; Navarro, José Miguel y Requena, Francisco (2015). «Migraciones interiores en España durante la crisis económica». En: Aja, Eliseo; Arango, Joaquín; Alonso, Josep Oliver; Sánchez-Montijano, Elena (eds.). Anuario de la Inmigración en España 2014. Flujos cambiantes, atonía institucional, 148-168. Barcelona: CIDOB.

Azevedo, Alda Botelho; López-Colás, Julián y Módenes, Juan Antonio (2016). "Home ownership in Southern European countries: Similarities and differences». Portuguese Journal of Social Science, 15 (2), 275-298. <https://doi.org/10.1386/pjss.15.2.275_1>

Bell, Martin; Blake, Marcus; Boyle, Paul; Duke-Williams, Oliver; Rees, Philip; Stillwell, John y Hugo, Graeme (2002). "Cross-national comparison of internal migration: issues and measures». Journal of the Royal Statistical Society: Series A (Statistics in Society), 165 (3), 435-464. <https://doi.org/10.1111/1467-985X.t01-1-00247>

Bell, Martin y Charles-Edwards, Elin (2013). Cross-national Comparisons of Internal Migration: An Update on Global Patterns and Trends. Technical Paper No. 2013/1. Nueva York: United Nations Department of Economic and Social Affairs (Population Division).

Bell, Martin; Charles-Edwards, Elin; Ueffing, Philipp; Stillwell, John; KupisZEwski, Marek y Kupiszewska, Dorota (2015). "Internal Migration and Development: Comparing Migration Intensities around the World». Population and Development Review, 41 (1), 33-58. <https://doi.org/10.1111/j.1728-4457.2015.00025.x>

Belot, Michèle; Boone, Jan y Ours, Jan van (2007). "Welfare-Improving Employment Protection». Economica, 74 (295), 381-396. <https://doi.org/10.1111/j.1468-0335.2006.00576.x>

Bentivogli, Chiara y Pagano, Patrizio (1999). «Regional Disparities and Labour Mobility: the Euro-11 versus the USA». Labour, 13, 737-760. <https://doi.org/10.1111/1467-9914.00113>

Bentolila, Samuel (2001). Las migraciones interiores en España. Documentos de trabajo 2001-07. Madrid: FEDEA.

- (1997). «La inmovilidad del trabajo en las regiones españolas». Papeles de Economía Española, 72, 168-175. 
Bernard, Aude y Bell, Martin (2018). «Educational selectivity of internal migrants». Demographic Research, 39 (29), 835-854. <https://doi.org/10.4054/demres.2018.39.29>

Bernard, Aude; Bell, Martin y Charles-Edwards, Elin (2014). «Life-course transitions and the age profile of internal migration». Population and Development Review, 40 (2), 231-239. <https://doi.org/10.1111/j.1728-4457.2014.00671.x>

Bernard, Aude; Bell, Martin y Cooper, Jim (2018). "Internal migration and education: A cross-national comparison». Migration, Displacement and Education: Building Bridges, Not Walls (Background paper prepared for the 2019 Global Education Monitoring Report). París: UNESCO. <https://doi.org/10.18356/d54ffdf7-en>

Bernard, Aude y Vidal, Sergi (2019). «Does moving in childhood and adolescence affect residential mobility in adulthood? An analysis of long-term individual residential trajectories in 11 European countries». Population, Space and Place, 26 (1), e2286. $<$ https://doi.org/10.1002/psp.2286>

Borjas, George J.; Bronars, Stephen G. y Trejo, Stephen J. (1992). «Self-selection and internal migration in the United States». Journal of Urban Economics, 32 (2), 159-185. <https://doi.org/10.1016/0094-1190(92)90003-4>

Bover, Olympia y Velilla, Pablo (1999). Migrations in Spain: historical background and current trends. Madrid: Banco de España.

Cabrer, Bernardí; Serrano, Guadalupe y Simarro, Rocío (2009). «Flujos migratorios y movilidad del capital humano». Investigaciones Regionales, 16, 5-42.

Castles, Stephen; Hass, Hein de y Miller, Mark J. (2014). The Age of Migration. International Population Movements in the Modern World. Nueva York: Palgrave Macmillan.

Cattaneo, Cristina (2007). "The self-selection in the migration process: What can we learn?». Serie Economia e Impresa, 52 (Liuc Papers, no 199).

Cheshire, Paul C. y Magrini, Stefano (2006). «Population growth in European cities: weather matters but only nationally». Regional Studies, 40, 23-37. <https://doi.org/10.1080/00343400500449259>

CHiswick, Barry (2000). «Are immigrants favorably self-selected? An economic analysis». En: Brettell, Caroline B. y Hollifield, James F. (eds.). Migration theory: Talking across disciplines, 63-82. Nueva York: Routledge.

Clarke, Rowan y Eyal, Katherine (2013). «Microeconomic determinants of spatial mobility in post-apartheid South Africa: Longitudinal evidence from the National Income Dynamics Study». Development Southern Africa, 31 (1), 168-194. <https://doi.org/10.1080/0376835x.2013.857592>

Cohen, Aron (1994). «Reflexiones sobre la dinámica reciente de las migraciones mediterráneas y sus determinantes». En: López-García, Bernabé y Montalbes, Juan (eds.). El Magreb tras la crisis del Golfo: transformaciones politicas y orden internacional, 41-60. Granada: Universidad de Granada.

Delgado-Urrecho, José María y Martínez-Fernández, Luis Carlos (2016). "La huella de la inmigración extranjera en las comunidades autónomas de menor crecimiento demográfico». Cuadernos Geográficos, 55 (2), 127-15.

Docquier, Frédéric y Marfouk, Abdelsman (2006). «International Migration by Educational Attainment (1990-2000)». En: Schiff, Maurice y Özden, Çaglar (eds.). International Migration, Remittances, and the Brain Drain, 151-199. 
Washington: The International Bank of Reconstruction and Development/ World Bank.

$<$ https://doi.org/10.1596/978-0-8213-6372-0>

Domingo, Andreu (2016). «Resiliencia y estrés demográfico en la Cataluña del siglo xxI». Perspectives Demogràfiques, 2, 1-4.

- (2018). Demografía y posverdad. Estereotipos, distorsiones y falsedades sobre la evolución de la población. Barcelona: Icaria.

Domingo, Andreu y Cabré, Anna (2015). «La demografía del siglo xxi. Evolución reciente y elementos prospectivos». En: Torres, Cristóbal (ed.). España 2015. Situación Social, 63-73. Madrid: CIS.

Domínguez-Mujica, Josefina y Pérez-García, Tanausú (2017). «The economic crisis and the Southern European migration model». En: Glorius, Birgit y DomínGuez-MujicA, Josefina (eds.). European Mobility in Time of Crisis. The new context of European South-North Migration, 17-48. Bielefeld: Transcript. <https://doi.org/10.14361/9783839434789-002>

Feliciano, Cynthia (2005). «Educational selectivity in US immigration: How do immigrants compare to those left behind?». Demography, 42 (1), 131-152. $<$ https://doi.org/10.1353/dem.2005.0001>

FIELding, Anthony J. (1992). «Migration and social mobility: South East England as an escalator region». Regional Studies, 26 (1), 1-15. <https://doi.org/10.1080/00343409212331346741>

Galeano, Juan Martín (2016). Asentamiento territorial de la población extranjera en España a inicios del siglo XXI: segregación residencial, concentración territorial y diversidad poblacional. Doctoral dissertation, Centre d'Estudis Demogràfics y Departament de Geografia (Universitat Autònoma de Barcelona). Barcelona.

García-Coll, Arlinda (2005). "Migraciones interiores y transformaciones territoriales». Papeles de Economía Española. Transformación Demográfica: Raíces y Consecuencias, 104, 76-91.

Gerolimeto, Margherita y Magrini, Stefano (2018). "State of the Art and Future Challenges of Interregional Migration Empirical. Research in Europe». En: BIAGI, Bianca; Faggian, Alessandra; RajBhandari, Isha y Venhorst, Viktor A. (eds.). New Frontiers in Interregional Migration Research, 87-104. Cham (Suiza): Springer.

Gil-Alonso, Fernando; Bayona-y-Carrasco, Jordi y Pujadas Rúbies, Isabel (2015). "Las migraciones internas de los extranjeros en España: dinámicas espaciales recientes bajo el impacto de la crisis». Boletin de la Asociación de Geógrafos Españoles, 69, 233-261.

<https://doi.org/10.21138/bage.1896>

Ginsburg, Carren; Bocquier, Philippe; Béguy, Donatien; Afolabi, Sulaimon; Augusto, Orvalho; Derra, Kerim; Odhiambo, Frank; Otiende, Mark; Soura, Abdramene; Zabré, Pascal; White, Michael J. y Collison, Mark (2016). «Human capital on the move: Education as a determinant of internal migration in selected INDEPTH surveillance populations in Africa». Demographic Research, 34 (30), 845-884. <https://doi.org/10.4054/demres.2016.34.30>

GonzÁlez-EnríQuez, Carmen (2013). ¿Emigran los españoles? Madrid: Real Instituto Elcano.

González-Enríquez, Carmen y Martínez-Romera, José Pablo (2017). «La emigración española cualificada tras la crisis. Una comparación con la italiana, griega y portuguesa». Migraciones, 43, 117-145.

<https://doi.org/10.14422/mig.i43.y2017.006> 
González-Ferrer, Amparo. (2013). «La nueva emigración española. Lo que sabemos y lo que no». Zoom Político, 18.

González-Leonardo, Miguel y López-Gay, Antonio (2019a). «El nuevo paradigma de las migraciones internas en España: migrantes urbanos más móviles y cualificados. El caso de Castilla y León». Scripta Nova. Revista Electrónica de Geografía y Ciencias Sociales, 23 (609).

<https://doi.org/10.1344/sn2019.23.21615>

- (2019b). «Emigración y fuga de talento en Castilla y León». Boletín de la Asociación de Geógrafos Españoles, 80 (2.612), 1-31.

<https://doi.org/10.21138/bage.2612>

González-Leonardo, Miguel; López-Gay, Antonio y Recaño, Joaquín (2019). "Descapitalización educativa y segunda oleada de despoblación». Perspectives Demogràfiques, 16, 1-4. Recuperado de <https://ced.uab.cat/PD/PerspectivesDemografiques_016_ESP.pdf $>$.

- (2020). «Selectividad migratoria y acumulación regional del capital humano cualificado en España». Investigaciones Regionales, 47, 113-133. <https://doi.org/10.38191/iirr-jorr.20.013>

Gould, William T. S. (1982). «Education and internal migration: A review and report. International». Journal of Educational Development, 1 (3), 103-111. <https://doi.org/10.1016/0738-0593(82)90047-5>

GreENWOOD, Michael J. (1975). «Research on internal migration in the United States: A survey». Journal of Economic Literature, 13 (2), 397-433.

Greenwood, Michael J. y Hunt, Gary L. (2003). "The early history of migration research». International Regional Science Review, 26 (1), 3-37. <https://doi.org/10.1177/0160017602238983>

Gropas, Ruby y Triandafyllidou, Anna (2014). Emigrating in times of crisis. Highlights and new data from an e-survey on high-skilled emigrants from Southern Europe and Ireland. Global Governance Programme, European, University Institute. Recuperado de <http://hdl.handle.net/1814/48384>.

Harris, John R. y Todaro, Michael P. (1970). "Migration, unemployment, and development: a two-sector analysis». American Economic Review, 60, 126-142.

Hatton, Timothy J. y Williamson, Jeffrey G. (2004). International Migration in the Long Run: Positive Selection, Negative Selection and Policy. Cambridge: National Bureau of Economic Research. <https://doi.org/10.3386/w10529>

Herrera-Ceballos, María Jesús (2014). «Migración cualificada de trabajadores de España al extranjero». En: Arango, Joaquín; Moya, David y Alonso, Josep Oliver (eds.). Anuario de la Inmigración en España 2013. Inmigración y emigración: mitos y realidades, 90-107. Barcelona: CIDOB.

LeE, Everett S. (1966). «A theory of migration». Demography, 3 (1), 47-57. $<$ https://doi.org/10.2307/2060063>

Long, Larry H. (1973). «Migration differentials by education and occupation: Trends and variations». Demography, 10 (2), 243-258. $<$ https://doi.org/10.2307/2060816>

López De Lera, Diego (2015). «Panorama de la migración internacional en España». En: Torres, Cristóbal (ed.). España 2015. Situación Social, 196-206. Madrid: CIS. López-Gay, Antonio (2004). «Intensidad y calendario de la movilidad residencial en la Unión Europea». Scripta Nova. Revista Electrónica de Geografía y Ciencias Sociales, 8 (174). 
- (2016a) «Atracción de talento y polarización socioeconómica en Barcelona». Perspectives Demogràfiques, 3.

- (2016b). «El advenimiento de las regiones metropolitanas maduras en España: retos demográficos y socioeconómicos en un nuevo contexto urbano». Panorama Social, 23, 179-196.

López-Gay, Antonio y Anadújar-Llosa, Andrea (2019, en prensa). «Cambios en la composición social de los barrios de Barcelona y Madrid: una mirada a través de los flujos migratorios y residenciales». En: Actas del XVI Congreso de Población en España. Granada: Editorial Comares.

Machin, Stephen; Salvanes, Kjell G.; Pelkonen, Panu (2012). «Education and mobility». Journal of the European Economic Association, 10 (2), 417-450. <https://doi.org/10.1111/j.1542-4774.2011.01048.x>

Maczulski, Terhi; Böckerman, Petri y Kosonen, Tuomas (2018). Job Displacement, Inter-Regional Mobility and Long-Term Earnings. Discussion Paper Series. Bonn (Alemania): IZA Institute for Labor Economics.

Malamud, Ofer; WozniaK, Abigail (2012). "The impact of college on migration evidence from the Vietnam generation». Journal of Human Resources, 47 (4), 913-950. <https://doi.org/10.3368/jhr.47.4.913>

Massey, Douglas S. (1987). "Understanding Mexican Migration to the United States». American Journal of Sociology, 92, 1.372-1.403. <https://doi.org/10.1086/228669>

- (1990). "Social structure, household strategies and the cumulative causation of migration». Population Index, 56, 3-26.

- (1999). "Why Does Immigration Occur? A Theoretical Synthesis». En: Hirschman, Charles; Kasinitz, Philip y Wind, Joshua de (eds.). Handbook of International Migration, 34-52. Nueva York: Russell Sage Foundation.

Massey, Douglas S. y Espinosa, Kristin E. (1997). "What is driving Mexico-US migration? A theoretical, empirical, and policy analysis». American Journal of Sociology, 102 (4), 939-999. <https://doi.org/10.1086/231037>

Molloy, Raven; Smith, Christopher S. y Wozniak, Abigail (2011). «Internal Migration in the United States». Journal of Economic Perspectives, 25 (3), 173-196. $<$ https://doi.org/10.1257/jep.25.3.173>

Muñoz-PÉrez, Francisco y IzQuierdo-Escribano, Antonio (1989). «L'Espagne, pays d'immigration». Population, 44, 257-289.

Myrdal, Gunnar (1957). Rich Lands and Poor. Nueva York: Harper and Row.

NAVARrete, Lorenzo. (2014). La emigración de los jóvenes españoles en el contexto de la crisis. Análisis de datos de un fenómeno difícil de cuantificar. Madrid: Gobierno de España.

OCDE (2007). International Migration Outlook 2007. París: OCDE.

Oswald, Andrew J. (1999). The Housing Market and Europe's Unemployment. Working paper. Warwick: University of Warwick.

OucHo, John (1998). "Recent internal migration processes in sub-Saharan Africa; determinants, consequences, and data adequacy issues». En: Bilsborrow, Richard E. (ed.). Migration, urbanization and development: New directions and issues, 89-120. Nueva York: UNPF / Kluwer Academic Publishers.

Palloni, Alberto; Massey, Douglas S.; Ceballos, Miguel; Espinosa, Kristin y SpitTel, Michael (2001). «Social capital and international migration: A test using information on family networks». American Journal of Sociology, 106 (5), 1.262-1.298 <https://doi.org/10.1086/320817> 
Partridge, Mark D. y Rickman, Dan S. (2003). «The waxing and waning of US regional economies: the chicken-egg of jobs versus people». Journal Urban Economics, 53, 76-97. <https://doi.org/10.1016/s0094-1190(02)00501-6>

- (2006). "An SVAR Model of Fluctuations in aggregate US migration flows and regional labor market flexibility». Southern Economic Journal, 72, 958-980. <https://doi.org/10.2307/20111863>

Prieto-Rosas, Victoria; Recaño, Joaquín y Quintero-Lesmes, Doris Cristina (2018). «Migration responses of immigrants in Spain during the Great Recession». Demographic Research, 38 (61), 1.885-1.932. <https://doi.org/10.4054/demres.2018.38.61>

Puga, María Dolores (2004). Estrategias residenciales de las personas de edad: movilidad y curso de vida. Barcelona: Fundación La Caixa.

Quinn, Michael A. y Rubb, Stephen (2005). "The importance of educationoccupation matching in migration decisions». Demography, 42 (1), 153-167. <https://doi.org/10.1353/dem.2005.0008>

Ravenstein, Ernest G. (1885). "The laws of migration». Journal of the Statistical Society of London, 48 (2), 167-235. <https://doi.org/10.2307/2979181>

ReCAÑo, Joaquín (2002). «La movilidad geográfica de la población extranjera en España: un fenómeno emergente». Cuadernos de Geografía, 75, 135-156.

- (2015). «Familia, género y migración interna en España». Revista de Demografía Histórica, 33 (2), 153-184.

- (2016). «La consolidación de las migraciones internas de inmigrantes como factor estructural de la movilidad geográfica de España». Panorama Social, 24, 49-71.

Recaño, Joaquín y Miguel, Verónica de (2012). "The internal migration of foreign-born population in Southern Europe: Demographic patterns and individual determinants». En: Finney, Nissa y Catney, Gemma (eds.). Minority internal migration in Europe, 239-262. Londres: Ashgate.

<https://doi.org/10.4324/9781315595528>

Reed, Holly E. (2013). "Moving across boundaries: Migration in South Africa, 19502000». Demography, 50 (1), 71-95. <https://doi.org/10.1007/s13524-012-0140-x>

Reher, David y Requena, Miguel (2011). «¿España en la encrucijada? Consideraciones sobre el cambio de ciclo migratorio". Revista Internacional de Sociología. La inmigración en España: perspectivas innovadoras. Monográfico, 1, 9-44. <https://doi.org/10.3989/ris.2011.im1.385>

ReHER, David y Silvestre, Javier (2011). «La movilidad interna de los inmigrantes en España. Un estudio basado en la Encuesta Nacional de Inmigrantes (ENI-2007)». Revista Internacional de Sociología, 69 (1), 167-188. <https://doi.org/10.3989/ris.2011.iM1.390>

Rendall, Michael S. y Parker, Susan W. (2014). "Two decades of negative educational selectivity of Mexican migrants to the United States». Population and Development Review, 40 (3), 421-446. <https://doi.org/10.1111/j.1728-4457.2014.00692.x>

Reques-Velasco, Pedro (2007). Atlas digital de la España universitaria. Santander: Universidad de Cantabria.

Rodríguez-Pose, Andrés y Ketterer Tobias D. (2012). «Do local amenities affect the appeal of regions in Europe for migrants?». Journal of Regional Science, 52, 535-561. <https://doi.org/10.1111/j.1467-9787.2012.00779.x> 
Rodríguez-Rodríguez, María de los Ángeles y Domínguez-MujicA, Josefina (2019). «Movilidad interior de los estudiantes universitarios españoles (2001-2015): una lectura geográfica». Cuadernos Geográficos, 58 (1), 300-320. <http://dx.doi.org/10.30827/cuadgeo.v58i1.6615>

Romero-Valiente, Juan Manuel y Hidalgo-Capitán, Antonio Luis (2014). «El subregistro consular: magnitudes y efectos en las estadísticas de emigración española». OBETS. Revista de Ciencias Sociales, 9, 377-407. <https://doi.org/10.14198/obets2014.9.2.06>

Roy, Andrew D. (1951). «Some thoughts on the distribution of earnings». Oxford Economic Papers, 3, 135-146.

Sánchez-Moral, Simón; Arellano, Alfonso y Díez-Pisonero, Roberto (2018). «Interregional mobility of talent in Spain: The role of job opportunities and qualities of places during the recent economic crisis». Environment and Planning A: Economy and Space, 50 (4), 789-808. <https://doi.org/10.1177/0308518X18761151>

Săseanu, Andreea S. y Petrescu, Raluca M. (2012). «Education and migration. The case of Romanian immigrants in Andalusia, Spain». Social and Behavioral Sciences, 46, 4.077-4.081. <https://doi.org/10.1016/j.sbspro.2012.06.201>

Schwartz, Aba (1973). "Interpreting the effect of distance on migration». Journal of Political Economy, 81 (5), 1.153-1.569. <https://doi.org/10.1086/260111>

Seers, Dudley; Schaffer, Bernard y Kiljunen, Marja-Liisa (1979). Underdeveloped Europe: Studies in Core - Periphery Relations. Brighton: Harvester.

SJAASTAD, Larry A. (1962). "The costs and returns of human migration». The Journal of Political Economy, 70 (5), 80-93.

SKeLDON, Ronald (2008). "International migration as a tool in development policy: A passing phase?». Population and Development Review, 34 (1), 1-18. <https://doi.org/10.1111/j.1728-4457.2008.00203.x>

SpeAre, Alden Jr y Harris, John (1986). «Education, earnings, and migration in Indonesia». Economic Development and Cultural Change, 34 (2), 223-244. $<$ https://doi.org/10.1086/451525>

Spilimbergo, Antonio y Ubeda, Luis (2004). «A Model of Multiple Equilibria in a Model of Labor Mobility». Journal of Development Economics, 73 (1), 107-123. <https://doi.org/10.1016/j.jdeveco.2002.11.001>

STARK, Oded y Bloom, David E. (1985). «The new economics of labour migration». American Economic Review, 75, 173-178.

Thomas, Dorothy S. (1938). Research memorandum on migration differentials. Brooklyn: Social Science Research Council.

Tremblay, Karine (2002) «Student mobility between and towards OECD countries: a comparative analysis». En: OECD (ed.). International mobility of the highly skilled, 39-67. París: OECD.

Triandafyllidou, Anna y Gropas, Ruby (2014). «Voting With Their Feet'. Highly Skilled Emigrants from Southern Europe». American Behavioral Scientist, 58, 1.614-1.633. <https://doi.org/10.1177/0002764214534665>

VReYer, Philippe de y Roubaud, François. (2013). Urban labor markets in sub-Saharan Africa. Washington DC: World Bank Publications (Africa Development Forum Series). <https://doi.org/10.1596/978-0-8213-9781-7> 
Williams, Allan M.; Baláz, Vladimir y Wallace, Clarie (2004). «International Labour Mobility and Uneven Regional Development in Europe: Human Capital, Knowledge and Entrepreneurship». Regional Studies, 11 (1), 27-46. $<$ https://doi.org/10.1177/0969776404039140>

Williams, Nathalie (2009). «Education, gender, and migration in the context of social change». Social Science Research, 38 (4), 883-896. <https://doi.org/10.1016/j.ssresearch.2009.04.005>

World BANK (2009). World Development Report 2009: Reshaping economic geography. Washington DC: World Bank.

Wozniak, Abigail (2010). «Are College Graduates More Responsive to Distant Labor Market Opportunities?». Journal of Human Resources, 45 (4), 944-970. $<$ https://doi.org/10.1353/jhr.2010.0030> 


\section{Anexo}

Tabla 1. Stocks y balances migratorios interprovinciales para la población autóctona de 25 a 34 años, por nivel educativo, 2011

\begin{tabular}{|c|c|c|c|c|c|c|c|c|c|c|c|c|}
\hline \multirow[b]{2}{*}{ Provincia } & \multicolumn{6}{|c|}{ No universitarios } & \multicolumn{6}{|c|}{ Universitarios } \\
\hline & Emi. & $\mathrm{I}_{\mathrm{e}}$ & Inm. & $\mathrm{I}_{\text {cap }}$ & Balance & $\mathrm{I}_{\text {capN }}$ & Emi. & $\mathrm{I}_{\mathrm{e}}$ & Inm. & $\mathrm{I}_{\text {cap }}$ & Balance & $\mathrm{I}_{\text {capN }}$ \\
\hline Soria & 1.388 & 0,24 & 1.475 & 0,34 & 88 & 0,02 & 2.513 & 0,52 & 588 & 0,25 & -1.924 & $-0,82$ \\
\hline Zamora & 4.447 & 0,29 & 2.441 & 0,22 & -2.005 & $-0,18$ & 4.106 & 0,48 & 1.309 & 0,30 & -2.797 & $-0,63$ \\
\hline Ávila & 3.692 & 0,30 & 3.759 & 0,44 & 66 & 0,01 & 3.370 & 0,48 & 1.246 & 0,34 & -2.124 & $-0,58$ \\
\hline Cuenca & 4.598 & 0,27 & 3.715 & 0,30 & -882 & $-0,07$ & 4.360 & 0,48 & 1.703 & 0,36 & -2.657 & $-0,56$ \\
\hline Palencia & 3.804 & 0,24 & 2.594 & 0,21 & -1.209 & $-0,10$ & 3.366 & 0,46 & 1.166 & 0,29 & & $-0,55$ \\
\hline Salamanca & 7.385 & 0,26 & 4.219 & 0,20 & -3.166 & $-0,15$ & 8.419 & 0,45 & 3.729 & 0,36 & & $-0,46$ \\
\hline Teruel & 3.377 & 0,32 & 2.980 & 0,42 & -397 & $-0,06$ & 2.500 & 0,48 & 1.322 & 0,50 & -1.177 & $-0,44$ \\
\hline León & 8.933 & 0,21 & 6.271 & 0,18 & -2.662 & $-0,08$ & 8.330 & 0,39 & 2.925 & 0,23 & 05 & $-0,42$ \\
\hline Jaén & 12.592 & 0,18 & 6.981 & 0,12 & -5.611 & $-0,10$ & 10.697 & 0,36 & 2.967 & 0,15 & & $-0,40$ \\
\hline Orense & 6.310 & 0,23 & 2.939 & 0,14 & -3.370 & $-0,16$ & 5.037 & 0,37 & 1.755 & 0,21 & -3.282 & $-0,38$ \\
\hline Segovia & 2.682 & 0,23 & 2.708 & 0,31 & 26 & 0,00 & 2.696 & 0,42 & 1.396 & 0,38 & & $-0,35$ \\
\hline Burgos & 6.313 & 0,23 & 5.726 & 0,27 & -588 & $-0,03$ & 6.154 & 0,37 & 2.921 & 0,28 & & $-0,31$ \\
\hline uesca & 417 & 0,28 & 4.289 & 0,39 & -128 & $-0,01$ & 3.180 & 0,37 & 1.841 & 0,34 & & $-0,25$ \\
\hline Cáceres & 9.262 & 0,24 & 6.892 & 0,24 & -2.370 & $-0,08$ & 5.935 & 0,36 & 3.525 & & & $-0,23$ \\
\hline Lugo & 395 & 0,15 & 4.328 & 0,17 & -67 & 0,00 & 4.213 & 0,33 & 2.314 & 0,27 & & $-0,22$ \\
\hline izcay & 20.884 & 0,22 & 6.574 & 0,09 & 4.310 & $-0,20$ & 15.550 & 0,24 & 4.840 & 0,10 & & $-0,22$ \\
\hline Córdobs & 165 & 0,17 & 7.522 & 0,11 & & $-0,09$ & & 0,28 & 4.581 & & & $-0,20$ \\
\hline Badajoz & 943 & 0,16 & 8.372 & 0,15 & -2 & $-0,04$ & 7.858 & 0,28 & 4.209 & 0,21 & & $-0,18$ \\
\hline Áuipúzco & 608 & 0,21 & 4.344 & 0,10 & -7.263 & $-0,17$ & 8.598 & 0,23 & 3.787 & 0,13 & & $-0,16$ \\
\hline sturias & 408 & 0,12 & 6.886 & 0,09 & -4.5 & $-0,06$ & & 0,23 & 5.040 & & & $-0,16$ \\
\hline ádiz & 18.320 & 0,13 & 13.682 & 0,11 & -4 . & $-0,04$ & 86 & 0,26 & 6.644 & 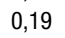 & & $-0,16$ \\
\hline Ciudad & 8.630 & 0,17 & 6.939 & 0,17 & 2 & $-0,04$ & & 0,30 & 3.946 & 027 & & $-0,16$ \\
\hline Lérida & 4.927 & 0,17 & 6.252 & 0,26 & & & & 0,29 & 3.165 & & & $-0,15$ \\
\hline Albacete & 7.044 & 0,19 & 4.925 & 0,16 & -2. & $-0,07$ & 4.199 & 0,26 & 2.980 & 0,25 & & $-0,10$ \\
\hline La Rioja & 3.371 & 0,16 & 4.990 & 0,27 & 1.620 & 0,09 & 3.326 & 0,28 & 2.503 & 0,30 & 23 & $-0,10$ \\
\hline Zaras & & 0,13 & 10.421 & & & & & 0,24 & 6.833 & & & $-0,09$ \\
\hline Cantak & 841 & 0,11 & 6.511 & 0,14 & 670 & 00 & 5.576 & 0,25 & 4.124 & 0,24 & & $-0,09$ \\
\hline Granada & 14.820 & 0,18 & 11.7 & 0,17 & -3.026 & $-0,04$ & 99 & 0,28 & 9.227 & 0,32 & & $-0,08$ \\
\hline Huelva & 122 & 0,08 & & 0,16 & & & & 0,23 & 3.355 & & & $-0,05$ \\
\hline Valladolid & 590 & 0,18 & 6.481 & 0,18 & -1 & $-0,03$ & 7.272 & 0,29 & 6.487 & 0,37 & -785 & $-0,04$ \\
\hline Pontev & 11.074 & 0,11 & 8.514 & 0,10 & -2 & $-0,03$ & 6.899 & 0,21 & 6.156 & 0,23 & -743 & $-0,03$ \\
\hline La Coruña & & 0,12 & & & & & & 0,21 & 8.5 & & & $-0,03$ \\
\hline Valencia & 20.082 & 0,10 & 19.051 & 0,10 & -1.032 & $-0,01$ & 14.973 & 0,14 & 13.326 & 0,14 & -1.647 & $-0,02$ \\
\hline Álava & 5.246 & 0,22 & 5.630 & 0,30 & & & & 0,28 & 3.976 & & -6 & 0,00 \\
\hline arcelon & 908 & 0,16 & 30.326 & 0,08 & 40.582 & $-0,11$ & & 0,14 & 33.222 & & .046 & 0,01 \\
\hline Murcia & 9.740 & 0,08 & 14.131 & 0,12 & 4.391 & 0,04 & 6.658 & 0,13 & 7.505 & 0,17 & 846 & 0,02 \\
\hline Navarra & 5.194 & 0,13 & 7.019 & 0,20 & 1.825 & & 5.096 & 0,18 & 5.804 & 026 & 709 & 0,03 \\
\hline Gerona & 5.717 & 0,13 & 15.354 & 0,40 & & 0,25 & & 0,22 & 5.812 & & 723 & 0,04 \\
\hline Las Palma & 5.702 & 0,06 & 12.802 & 0,13 & 7.100 & 0,07 & 4.369 & 0,14 & 5.939 & 0,22 & 1.570 & 0,06 \\
\hline Alicante & 10.655 & 0,08 & 28.522 & 0,23 & 17.867 & & 8.366 & 0,15 & 11.314 & 024 & & 0,06 \\
\hline Sta. Cruz & & 0,04 & 9.066 & 0,11 & & 0,07 & 3.292 & 0,11 & 5.557 & 0,21 & 2.265 & 0,09 \\
\hline Sevilla & 18.643 & 0,09 & 17.610 & 0,10 & -1.033 & $-0,01$ & 10.911 & 0,15 & 17.257 & 0,27 & 6.347 & 0,10 \\
\hline Tarrago & 7.743 & 0,15 & 18.134 & 0,41 & 10.391 & 0,23 & 5.901 & 0,21 & 8.097 & 0,37 & 2.196 & 0,10 \\
\hline Toledo & 9.135 & 0,19 & 28.407 & 0,72 & 19.272 & 0,49 & 6.787 & 0,33 & 8.464 & 0,62 & 1.678 & 0,12 \\
\hline Castellón & 3.515 & 0,09 & 11.387 & 0,31 & 7.872 & 0,22 & 3.006 & 0,16 & 5.431 & 0,34 & 2.424 & 0,15 \\
\hline Almerí & 4.855 & 0,09 & 11.118 & 0,23 & 6.263 & 01 & 3.874 & 0,19 & 6.382 & 0,39 & 2.508 & 0,15 \\
\hline Málaga & 9.141 & 0,07 & 24.719 & 0,20 & 15.578 & 0,13 & 6.585 & 0,15 & 13.670 & 0,36 & 7.085 & 0,19 \\
\hline Madrid & 80.429 & 0,18 & 56.971 & 0,16 & -23.458 & $-0,07$ & 37.390 & 0,13 & 92.289 & 0,38 & 54.899 & 0,22 \\
\hline Baleares & 5.880 & 0,08 & 23.945 & 0,35 & 18.065 & 0,26 & 3.776 & 0,12 & 10.186 & 0,36 & 6.410 & 0,23 \\
\hline Guadalajara & 2.428 & 0,21 & 12.548 & 1,38 & 10.120 & 1,11 & 1.790 & 0,28 & 4.870 & 1,07 & 3.080 & 0,67 \\
\hline
\end{tabular}

Fuente: Censo de Población de 2011 (Instituto Nacional de Estadística). 
Tabla 2. Stocks de población alóctona entre 25 a 34 años por inmigración directa desde el exterior, inmigración interna y emigración interna, según el nivel educativo, 2011

\begin{tabular}{|c|c|c|c|c|c|c|c|c|c|c|c|c|}
\hline \multirow[b]{3}{*}{ Provincia } & \multicolumn{6}{|c|}{ No universitarios } & \multicolumn{6}{|c|}{ Universitarios } \\
\hline & \multicolumn{2}{|c|}{ Inm. exterior } & \multicolumn{2}{|c|}{ Inm.interna } & \multicolumn{2}{|c|}{ Em. Interna } & \multicolumn{2}{|c|}{ Inm. exterior } & \multicolumn{2}{|c|}{ Inm.interna } & \multicolumn{2}{|c|}{ Em. interna } \\
\hline & Inm. & $\mathrm{I}_{\text {cap }}$ & Inm. & $\mathrm{I}_{\text {cap }}$ & Emi. & $\mathrm{I}_{\mathrm{e}}$ & Inm. & $\mathrm{I}_{\text {cap }}$ & Inm. & $\mathrm{I}_{\text {cap }}$ & Emi. & $\mathrm{I}_{\mathrm{e}}$ \\
\hline Zamora & 1.487 & 0,13 & 326 & 0,03 & 440 & 0,23 & 74 & 0,02 & 75 & 0,02 & 115 & 0,61 \\
\hline Badajoz & 4.421 & 0,08 & 1.652 & 0,03 & 879 & 0,17 & 460 & 0,02 & 299 & 0,01 & 263 & 0,36 \\
\hline Cáceres & 2.270 & 0,07 & 699 & 0,02 & 1.764 & 0,44 & 334 & 0,03 & 167 & 0,02 & 173 & 0,34 \\
\hline Soria & 1.430 & 0,30 & 680 & 0,14 & 334 & 0,19 & 82 & 0,03 & 60 & 0,03 & 64 & 0,44 \\
\hline Jaén & 3.092 & 0,05 & 1.513 & 0,03 & 1.782 & 0,37 & 720 & 0,04 & 323 & 0,02 & 291 & 0,29 \\
\hline Valladolid & 5.058 & 0,14 & 1.490 & 0,04 & 1.202 & 0,19 & 758 & 0,04 & 328 & 0,02 & 486 & 0,39 \\
\hline Ávila & 1.895 & 0,20 & 686 & 0,07 & 642 & 0,25 & 163 & 0,04 & 79 & 0,02 & 75 & 0,31 \\
\hline Cádiz & 6.752 & 0,05 & 1.969 & 0,02 & 2.017 & 0,23 & 1.729 & 0,05 & 558 & 0,02 & 733 & 0,30 \\
\hline Vizcaya & 14.316 & 0,19 & 3.022 & 0,04 & 1.751 & 0,11 & 2.528 & 0,05 & 692 & 0,01 & 688 & 0,21 \\
\hline Cuenca & 4.514 & 0,34 & 1.502 & 0,11 & 1.536 & 0,25 & 265 & 0,05 & 294 & 0,06 & 264 & 0,50 \\
\hline Lugo & 3.060 & 0,12 & 461 & 0,02 & 675 & 0,18 & 450 & 0,05 & 138 & 0,02 & 111 & 0,20 \\
\hline Sevilla & 12.680 & 0,07 & 3.350 & 0,02 & 2.711 & 0,18 & 3.718 & 0,06 & 898 & 0,01 & 1.056 & 0,22 \\
\hline Huelva & 8.235 & 0,17 & 1.894 & 0,04 & 2.465 & 0,23 & 862 & 0,06 & 72 & 0,00 & 406 & 0,32 \\
\hline Palencia & 1.263 & 0,10 & 340 & 0,03 & 292 & 0,19 & 257 & 0,06 & 36 & 0,01 & 44 & 0,15 \\
\hline Asturias & 10.165 & 0,13 & 1.825 & 0,02 & 1.473 & 0,13 & 2.180 & 0,06 & 576 & 0,02 & 1.274 & 0,37 \\
\hline León & 4.977 & 0,14 & 874 & 0,03 & 1.636 & 0,25 & 811 & 0,06 & 371 & 0,03 & 371 & 0,31 \\
\hline Ciudad Real & 6.417 & 0,15 & 1.637 & 0,04 & 1.744 & 0,21 & 959 & 0,06 & 200 & 0,01 & 114 & 0,11 \\
\hline Córdoba & 3.597 & 0,05 & 1.051 & 0,02 & 2.060 & 0,36 & 1.584 & 0,07 & 180 & 0,01 & 490 & 0,24 \\
\hline Pontevedra & 8.120 & 0,09 & 1.479 & 0,02 & 1.524 & 0,16 & 1.896 & 0,07 & 370 & 0,01 & 555 & 0,23 \\
\hline Guipúzcoa & 7.018 & 0,16 & 1.095 & 0,02 & 1.079 & 0,13 & 2.143 & 0,07 & 379 & 0,01 & 349 & 0,14 \\
\hline Salamanca & 3.109 & 0,14 & 640 & 0,03 & 1.235 & 0,28 & 755 & 0,07 & 220 & 0,02 & 485 & 0,39 \\
\hline Burgos & 6.073 & 0,27 & 1.310 & 0,06 & 1.273 & 0,17 & 757 & 0,07 & 131 & 0,01 & 244 & 0,24 \\
\hline La Coruña & 9.148 & 0,10 & 1.807 & 0,02 & 1.822 & 0,17 & 2.791 & 0,08 & 802 & 0,02 & 515 & 0,16 \\
\hline Cantabria & 6.190 & 0,13 & 1.067 & 0,02 & 1.385 & 0,18 & 1.624 & 0,09 & 314 & 0,02 & 250 & 0,13 \\
\hline Teruel & 3.123 & 0,38 & 482 & 0,06 & 1.024 & 0,25 & 284 & 0,09 & 152 & 0,05 & 258 & 0,48 \\
\hline La Rioja & 8.499 & 0,44 & 2.323 & 0,12 & 1.509 & 0,15 & 811 & 0,09 & 305 & 0,04 & 344 & 0,30 \\
\hline Albacete & 5.410 & 0,18 & 1.136 & 0,04 & 2.781 & 0,34 & 1.142 & 0,10 & 340 & 0,03 & 250 & 0,18 \\
\hline Toledo & 12.938 & 0,30 & 6.338 & 0,14 & 4.322 & 0,25 & 1.508 & 0,10 & 847 & 0,05 & 824 & 0,35 \\
\hline Navarra & 13.700 & 0,36 & 2.773 & 0,07 & 1.523 & 0,10 & 2.406 & 0,10 & 600 & 0,03 & 403 & 0,14 \\
\hline Granada & 12.473 & 0,18 & 1.669 & 0,02 & 2.996 & 0,19 & 3.096 & 0,10 & 698 & 0,02 & 935 & 0,23 \\
\hline Murcia & 38.338 & 0,32 & 8.517 & 0,07 & 7.559 & 0,16 & 4.434 & 0,10 & 1.179 & 0,03 & 1.032 & 0,19 \\
\hline Huesca & 4.523 & 0,36 & 1.423 & 0,11 & 1.586 & 0,26 & 604 & 0,10 & 144 & 0,02 & 416 & 0,41 \\
\hline Orense & 4.111 & 0,20 & 1.099 & 0,05 & 976 & 0,19 & 925 & 0,11 & 29 & 0,00 & 337 & 0,27 \\
\hline Valencia & 47.217 & 0,25 & 9.731 & 0,05 & 6.092 & 0,11 & 11.677 & 0,12 & 2.206 & 0,02 & 1.342 & 0,10 \\
\hline Segovia & 3.165 & 0,34 & 897 & 0,10 & 870 & 0,22 & 467 & 0,12 & 80 & 0,02 & 184 & 0,28 \\
\hline Álava & 4.100 & 0,21 & 2.144 & 0,11 & 442 & 0,10 & 1.350 & 0,12 & 432 & 0,04 & 151 & 0,10 \\
\hline Zaragoze & 24.000 & 0,41 & 4.594 & 0,08 & 3.505 & 0,13 & 3.753 & 0,12 & 782 & 0,03 & 811 & 0,18 \\
\hline Lérida & 14.214 & 0,56 & 3.133 & 0,12 & 2.466 & 0,15 & 1.604 & 0,13 & 330 & 0,03 & 447 & 0,22 \\
\hline Guadalajara & 5.559 & 0,49 & 4.075 & 0,36 & 1.529 & 0,22 & 750 & 0,14 & 653 & 0,12 & 220 & 0,23 \\
\hline Almería & 26.024 & 0,51 & 4.036 & 0,08 & 7.046 & 0,21 & 2.599 & 0,15 & 512 & 0,03 & 872 & 0,25 \\
\hline Castellón & 16.470 & 0,41 & 2.777 & 0,07 & 2.665 & 0,14 & 2.760 & 0,16 & 415 & 0,02 & 526 & 0,16 \\
\hline Alicante & 40.942 & 0,31 & 9.258 & 0,07 & 6.977 & 0,15 & 8.254 & 0,17 & 1.666 & 0,03 & 1.792 & 0,18 \\
\hline Las Palmas & 20.946 & 0,21 & 3.047 & 0,03 & 3.824 & 0,15 & 5.131 & 0,18 & 520 & 0,02 & 728 & 0,12 \\
\hline Málaga & 27.590 & 0,22 & 5.198 & 0,04 & 5.878 & 0,18 & 8.163 & 0,20 & 1.602 & 0,04 & 1.004 & 0,11 \\
\hline Tarragona & 20.036 & 0,41 & 5.331 & 0,11 & 3.215 & 0,14 & 4.834 & 0,20 & 798 & 0,03 & 1.160 & 0,19 \\
\hline Gerona & 25.902 & 0,61 & 5.104 & 0,12 & 3.320 & 0,11 & 4.364 & 0,22 & 913 & 0,05 & 946 & 0,18 \\
\hline Madrid & 181.016 & 0,49 & 18.887 & 0,05 & 31.898 & 0,15 & 61.075 & 0,23 & 6.808 & 0,03 & 6.861 & 0,10 \\
\hline Sta.Cruz de Tf. & 20.454 & 0,24 & 3.039 & 0,04 & 2.021 & 0,09 & 6.461 & 0,24 & 659 & 0,02 & 550 & 0,08 \\
\hline Baleares & 37.545 & 0,50 & 6.282 & 0,08 & 2.797 & 0,07 & 7.335 & 0,24 & 1.770 & 0,06 & 679 & 0,08 \\
\hline Barcelona & 132.248 & 0,36 & 13.773 & 0,04 & 16.776 & 0,11 & 57.177 & 0,28 & 5.152 & 0,03 & 4.788 & 0,08 \\
\hline
\end{tabular}

Fuente: Censo de Población de 2011 (Instituto Nacional de Estadística). 
Tabla 3. Balance migratorio provincial para la población de 25 a 34 años (saldo interprovincial de autóctonos + stock de alóctonos), por nivel educativo, 2011

\begin{tabular}{|c|c|c|c|c|}
\hline \multirow[b]{2}{*}{ Provincia } & \multicolumn{2}{|c|}{ No universitarios } & \multicolumn{2}{|c|}{ Universitarios } \\
\hline & Balance & $\mathrm{I}_{\text {capN }}$ & Balance & $\mathrm{I}_{\text {capN }}$ \\
\hline Soria & 2.197 & 0,50 & -1.783 & $-0,76$ \\
\hline Zamora & -192 & $-0,02$ & -2.648 & $-0,60$ \\
\hline Ávila & 2.647 & 0,31 & -1.881 & $-0,51$ \\
\hline Palencia & 393 & 0,03 & -1.907 & $-0,48$ \\
\hline Cuenca & 5.133 & 0,41 & -2.098 & $-0,44$ \\
\hline Salamanca & 582 & 0,03 & -3.715 & $-0,36$ \\
\hline Jaén & -1.006 & $-0,02$ & -6.688 & $-0,34$ \\
\hline León & 3.189 & 0,09 & -4.224 & $-0,32$ \\
\hline Teruel & 3.209 & 0,46 & -741 & $-0,28$ \\
\hline Orense & 1.840 & 0,09 & -2.328 & $-0,27$ \\
\hline Burgos & 6.796 & 0,31 & -2.345 & $-0,23$ \\
\hline Segovia & 4.088 & 0,47 & -753 & $-0,20$ \\
\hline Cáceres & 599 & 0,02 & -1.909 & $-0,18$ \\
\hline Lugo & 3.455 & 0,14 & -1.310 & $-0,15$ \\
\hline Vizcaya & 3.029 & 0,04 & -7.490 & $-0,15$ \\
\hline Badajoz & 3.502 & 0,06 & -2.890 & $-0,14$ \\
\hline Córdoba & -1.995 & $-0,03$ & -3.188 & $-0,13$ \\
\hline Huesca & 5.818 & 0,52 & -591 & $-0,11$ \\
\hline Cádiz & 4.082 & 0,03 & -3.355 & $-0,10$ \\
\hline Asturias & 7.468 & 0,09 & -2.948 & $-0,08$ \\
\hline Ciudad Real & 6.363 & 0,15 & -1.213 & $-0,08$ \\
\hline Guipúzcoa & 849 & 0,02 & -2.289 & $-0,08$ \\
\hline Lérida & 18.672 & 0,78 & 76 & 0,01 \\
\hline Huelva & 13.366 & 0,29 & 195 & 0,01 \\
\hline Valladolid & 5.439 & 0,15 & 301 & 0,02 \\
\hline Albacete & 4.428 & 0,15 & 262 & 0,02 \\
\hline Cantabria & 7.927 & 0,17 & 486 & 0,03 \\
\hline La Rioja & 12.441 & 0,68 & 293 & 0,04 \\
\hline Granada & 11.115 & 0,16 & 1.422 & 0,05 \\
\hline Zaragoza & 30.604 & 0,54 & 1.594 & 0,05 \\
\hline Pontevedra & 7.039 & 0,08 & 1.523 & 0,06 \\
\hline La Coruña & 8.045 & 0,09 & 2.645 & 0,07 \\
\hline Valencia & 55.916 & 0,30 & 12.236 & 0,13 \\
\hline Murcia & 51.246 & 0,43 & 6.460 & 0,15 \\
\hline Navarra & 18.299 & 0,51 & 3.714 & 0,16 \\
\hline Sevilla & 14.998 & 0,08 & 10.963 & 0,17 \\
\hline Álava & 6.628 & 0,36 & 1.776 & 0,17 \\
\hline Las Palmas & 31.094 & 0,32 & 7.222 & 0,27 \\
\hline Alicante & 68.067 & 0,56 & 12.867 & 0,28 \\
\hline Toledo & 38.549 & 0,98 & 4.033 & 0,30 \\
\hline Barcelona & 105.439 & 0,29 & 64.376 & 0,32 \\
\hline Gerona & 40.642 & 1,06 & 6.000 & 0,34 \\
\hline Almería & 36.323 & 0,74 & 5.619 & 0,35 \\
\hline Castellón & 27.118 & 0,74 & 5.600 & 0,35 \\
\hline Tarragona & 35.757 & 0,80 & 7.827 & 0,36 \\
\hline Santa Cruz de Tenerife & 29.043 & 0,35 & 9.386 & 0,36 \\
\hline Málaga & 48.366 & 0,39 & 16.850 & 0,44 \\
\hline Madrid & 176.444 & 0,49 & 122.782 & 0,50 \\
\hline Baleares & 61.892 & 0,90 & 15.515 & 0,55 \\
\hline Guadalajara & 19.754 & 2,17 & 4.484 & 0,98 \\
\hline
\end{tabular}

Fuente: Censo de Población de 2011 (Instituto Nacional de Estadística). 
Tabla 4. Regresión logística para la emigración interprovincial de la población entre 25 y 34 años, por nivel educativo (modelo 2 de la figura 4)

\begin{tabular}{|c|c|c|c|c|c|c|}
\hline \multirow{2}{*}{$\frac{\text { Variables explicativas }}{\text { País de nacimiento }}$} & \multicolumn{2}{|c|}{ Total } & \multicolumn{2}{|c|}{ No universitarios } & \multicolumn{2}{|c|}{ Universitarios } \\
\hline & & & & & & \\
\hline España & 1,000 & & 1,000 & & 1,000 & \\
\hline Extranjero & 1,214 & 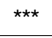 & 1,347 & 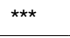 & 0,938 & * \\
\hline \multicolumn{7}{|l|}{ Sexo } \\
\hline Hombre & 1,000 & & 1,000 & & 1,000 & \\
\hline Mujer & 0,933 & $\star \star \star \star ~$ & 0,899 & 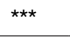 & 0,927 & $\star \star \star \star ~$ \\
\hline \multicolumn{7}{|l|}{ Lugar de trabajo } \\
\hline Provincia de residencia & 1,000 & & 1,000 & & 1,000 & \\
\hline Otras provincias & 1,955 & 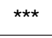 & 3,219 & 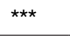 & 1,058 & * \\
\hline \multicolumn{7}{|l|}{ Estudia } \\
\hline No & 1,000 & & 1,000 & & 1,000 & \\
\hline Sí & 0,850 & $\star \star \star$ & 0,887 & 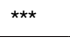 & 0,870 & $\star \star \star$ \\
\hline \multicolumn{7}{|l|}{ Estado civil } \\
\hline Soltero & 1,000 & & 1,000 & & 1,000 & \\
\hline Casado & 1,105 & 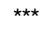 & 1,158 & 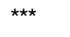 & 1,051 & $\star \star$ \\
\hline Separado, divorciado u otras situaciones & 1,256 & $\star \star \star \star ~$ & 1,425 & 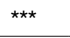 & 0,979 & n.s. \\
\hline \multicolumn{7}{|l|}{ Perfil ocupacional } \\
\hline Servicios personales & 1,000 & & 1,000 & & 1,000 & \\
\hline Ocupaciones elementales & 0,843 & 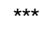 & 0,836 & 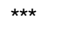 & 0,848 & * \\
\hline Cualif. industria, construcción y sector primario & 0,707 & $\star \star \star \star ~$ & 0,697 & 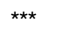 & 0,884 & * \\
\hline Contables y administrativo & 0,909 & $\star \star \star \star ~$ & 0,833 & 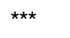 & 0,860 & $\star \star \star$ \\
\hline Técnicos y profesionales de apoyo & 1,023 & n.s. & 0,858 & 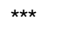 & 1,092 & * \\
\hline Técnicos y profesionales científicos e intelectuales & 1,353 & 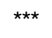 & 1,068 & n.s. & 1,160 & $\star \star \star$ \\
\hline Directivos y gerentes & 1,271 & $\star \star \star \star ~$ & 1,010 & n.s. & 1,243 & 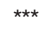 \\
\hline Desempleados & 1,042 & n.s. & 0,979 & n.s. & 1,045 & n.s. \\
\hline \multicolumn{7}{|l|}{ Sectores económicos } \\
\hline Servicios & 1,000 & & 1,000 & & 1,000 & \\
\hline Primario & 0,748 & $\star \star \star \star$ & 0,797 & 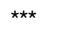 & 0,683 & $\star \star \star \star ~$ \\
\hline Secundario & 0,800 & $\star \star \star \star$ & 0,794 & 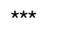 & 0,882 & $\star \star \star$ \\
\hline Construcción & 0,906 & $\star \star \star \star ~$ & 0,860 & $\star \star \star \star ~$ & 1,088 & * \\
\hline \multicolumn{7}{|l|}{ Tipo de provincia } \\
\hline Poco emisora y nivel educativo bajo & 1,000 & & 1,000 & & 1,000 & \\
\hline Poco emisora y nivel educativo medio & 1,086 & $\star \star \star \star$ & 1,094 & $\star \star \star$ & 1,056 & n.s. \\
\hline Poco emisora y nivel educativo alto & 1,010 & n.s. & 1,214 & 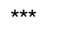 & 0,772 & 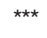 \\
\hline Emisión media y nivel educativo bajo & 1,819 & 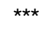 & 1,685 & 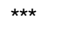 & 1,996 & 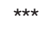 \\
\hline Emisión media y nivel educativo medio & 1,750 & $\star \star \star \star ~$ & 1,646 & 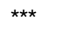 & 1,811 & 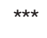 \\
\hline Emisión media y nivel educativo alto & 1,320 & 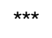 & 1,653 & 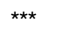 & 0,942 & * \\
\hline Emisora y nivel educativo bajo & 2,676 & 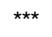 & 2,545 & $\star \star \star \star ~$ & 2,846 & 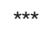 \\
\hline Emisora y nivel educativo medio & 3,092 & $\star \star \star \star ~$ & 2,836 & 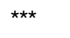 & 3,501 & $\star \star \star \star ~$ \\
\hline Emisora y nivel educativo alto & 3,195 & $\star \star \star \star ~$ & 2,411 & 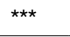 & 4,121 & $\star \star \star \star ~$ \\
\hline \multicolumn{7}{|l|}{ Parámetros del modelo } \\
\hline Constante & 0,128 & $\star \star \star \star ~$ & 0,109 & 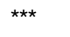 & 0,181 & 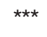 \\
\hline Chi-Cuadrado & \multicolumn{2}{|c|}{8488,5} & \multicolumn{2}{|c|}{5021,1} & \multicolumn{2}{|c|}{4048,3} \\
\hline-2 log de la verosimilitud & \multicolumn{2}{|c|}{2318826,8} & \multicolumn{2}{|c|}{1330980,4} & \multicolumn{2}{|c|}{964672,5} \\
\hline $\mathrm{R}^{2}$ de Cox y Snell & \multicolumn{2}{|c|}{0,028} & \multicolumn{2}{|c|}{0,027} & \multicolumn{2}{|c|}{0,037} \\
\hline $\mathrm{R}^{2}$ de Nagelkerke & \multicolumn{2}{|c|}{0,051} & & 051 & & 061 \\
\hline
\end{tabular}

Fuente: Censo de Población de 2011 (Instituto Nacional de Estadística). 
Tabla 5. Regresión logística para la emigración interprovincial de la población entre 25 y 34 años, por lugar de nacimiento (modelo 2 de la figura 5)

\begin{tabular}{|c|c|c|}
\hline Variables & Autóctonos & Extranjeros \\
\hline \multicolumn{3}{|l|}{ Educación } \\
\hline Primaria $0<$ & 1,027 n.s. & 0,978 n.s. \\
\hline Secundaria-CFGM & 1,000 & 1,000 \\
\hline Bachillerato-CFGS & $1,147^{\star \star \star}$ & 0,954 n.s. \\
\hline Diplomatura o grado & $1,264 * \star \star$ & 0,949 n.s. \\
\hline Licenciatura y máster $0>$ & $1,825^{\star \star \star}$ & 1,035 n.s. \\
\hline \multicolumn{3}{|l|}{ Sexo } \\
\hline Hombre & 1,000 & 1,000 \\
\hline Mujer & $0,945^{\star \star \star}$ & 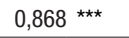 \\
\hline \multicolumn{3}{|l|}{ Estado civil } \\
\hline Soltero & 1,000 & 1,000 \\
\hline Casado & 1,128 *** & 0,987 n.s. \\
\hline Separado, divorciado u otras situaciones & $1,308^{\star \star \star}$ & 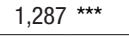 \\
\hline \multicolumn{3}{|l|}{ Lugar de trabajo } \\
\hline Provincia de residencia & 1,000 & 1,000 \\
\hline Otras provincias & 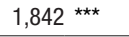 & $2,587^{\star \star \star}$ \\
\hline \multicolumn{3}{|l|}{ Estudia } \\
\hline No & 1,000 & 1,000 \\
\hline Sí & $0,894 * \star \star$ & 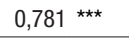 \\
\hline \multicolumn{3}{|l|}{ Perfil ocupacional } \\
\hline Servicios personales & 1,000 & 1,000 \\
\hline Ocupaciones elementales & $0,824 * \star \star$ & 0,919 * \\
\hline Cualif. industria, construcción y sector primario & $0,691 * \star \star$ & 0,889 * \\
\hline Contables y administrativo & $0,793^{\star \star \star}$ & 0,896 n.s. \\
\hline Técnicos y profesionales de apoyo & $0,907 * \star \star$ & 0,963 n.s. \\
\hline Técnicos y profesionales científicos e intelectuales & 0,990 n.s. & 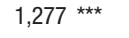 \\
\hline Directivos y gerentes & 1,006 n.s. & 1,204 n.s. \\
\hline Desempleados & 0,954 n.s. & 1,004 n.s. \\
\hline \multicolumn{3}{|l|}{ Sectores económicos } \\
\hline Servicios & 1,000 & 1,000 \\
\hline Primario & $0,609 * \star \star$ & 0,910 n.s. \\
\hline Secundario & $0,809 * \star \star$ & 0,854 ** \\
\hline Construcción & 0,934 ** & 0,933 n.s. \\
\hline \multicolumn{3}{|l|}{ Tipo de provincia } \\
\hline Poco emisora y nivel educativo bajo & 1,000 & 1,000 \\
\hline Poco emisora y nivel educativo medio & 1,068 ** & $1,152 * \star$ \\
\hline Poco emisora y nivel educativo alto & 1,069 ** & $0,687^{\star * \star}$ \\
\hline Emisión media y nivel educativo bajo & $1,839 \star \star \star *$ & 1,808 *** \\
\hline Emisión media y nivel educativo medio & 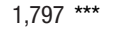 & 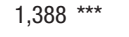 \\
\hline Emisión media y nivel educativo alto & 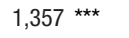 & 1,000 n.s. \\
\hline Emisora y nivel educativo bajo & $2,695 * \star \star$ & 2,926 *** \\
\hline Emisora y nivel educativo medio & $3,204 \star \star \star *$ & 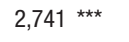 \\
\hline Emisora y nivel educativo alto & $3,395 * \star \star$ & $1,918^{\star \star \star}$ \\
\hline
\end{tabular}


Tabla 5. Regresión logística para la emigración interprovincial de la población entre 25 y 34 años, por lugar de nacimiento (modelo 2 de la figura 5) (continuación)

\begin{tabular}{lcc}
\hline Variables & Autóctonos & Extranjeros \\
\hline Región de nacimiento & & 1,000 \\
Europa Occidental + desarrollados de la OCDE & $1,201^{* \star \star}$ \\
Europa del Este & & $1,325^{\star \star \star}$ \\
América Latina & & $1,602^{\star \star \star}$ \\
Magreb & & $2,693^{* \star *}$ \\
África subsahariana & & $3,090^{\star \star \star}$ \\
Asia y Oriente Medio & & \\
\hline Parámetro del modelo & $0,108 * \star$ & $0,147^{\star \star \star}$ \\
Constante & 8806,6 & 1500,1 \\
Chi-Cuadrado & 1938373,2 & 362145,4 \\
-2 log de la verosimilitud & 0,035 & 0,033 \\
$\mathrm{R}^{2}$ de Cox y Snell & 0,062 & 0,058 \\
$\mathrm{R}^{2}$ de Nagelkerke & & \\
\hline
\end{tabular}

Fuente: Censo de Población de 2011 (Instituto Nacional de Estadística). 
